\title{
"Aerogels of enzymatically oxidized galactomannans from leguminous plants: versatile delivery systems of antimicrobial peptides and enzymes"
}

\author{
Paola Campia^, Erika Ponzini ${ }^{\circ}$, Bianca Rossi*, Stefano Farris ${ }^{\#}$, Tiziana Silvetti^, \\ Luca Merlini*, Milena Brasca^, Rita Grandori ${ }^{\circ}$ and Yves M. Galante*
}

^Istituto di Scienze delle Produzioni Alimentari, C.N.R.,

Via Celoria2, 20133 Milano, Italy. paola.campia@ispa.cnr.it milena.brasca@ispa.cnr.it tiziana.silvetti@ispa.cnr.it

${ }^{\circ}$ Department of Biotechnology and Biosciences University of Milano-Bicocca (UNIMIB) Piazza della Scienza 2, 20126, Milano, Italy. erika.ponzini@unimib.it rita.grandori@unimib.it

"PackLAB, Unimi Food Packaging Laboratory, DeFENS; Dept. of Food, Environmental and Nutritional Sciences; University of Milan Via Celoria 2, 20133 Milano, Italy. stefano.farris@unimi.it

* Istituto di Chimica del Riconoscimento Molecolare, C.N.R.,

Via Mario Bianco 9, 20131 Milano, Italy. bianca.rossi@polimi.it luca.merlini@icrm.cnr.it

Correspondence should be addressed to:

Y.M. Galante

Istituto di Chimica del Riconoscimento Molecolare, C.N.R.,

Via Mario Bianco 9, 20131 Milano, Italy.

Telephone number: +393358477648

e-mail address: $\quad$ yves.galante@icrm.cnr.it

Running title: Aerogels from oxidized leguminous galactomannans as delivery systems 
50 We describe aerogels obtained by laccase/TEMPO-oxidation and lyophilization of galactomannans

51 (GM) from fenugreek, sesbania and guar. Enzymatic oxidation of GM in aqueous solution caused viscosity increase up to fifteen-fold, generating structured, elastic, stable hydrogels, presumably due to establishment of hemiacetalic bonds between newly formed carbonyl groups and free hydroxyl groups. Upon lyophilization, water-insoluble aerogels were obtained, whose mechanical properties and porosity were investigated.

Active principles were absorbed into the aerogels from aqueous solutions and, following rinsing, blotting, re-lyophilization, were released in an appropriate medium. The release of the antibiotic polymyxin B was tested against six different Gram-negative bacterial strains, of the antimicrobial peptide nisin against two Gram-positive and of the muraminidase lysozyme against one anaerobic strain. Protease and lipase release in solution from "enzyme loaded" aerogels was monitored by the increase in enzymatic activity.

62 These biomaterials could represent new versatile, biocompatible "delivery systems" of actives for 63 biomedical and industrial applications.

64

65 Keywords: galactomannans; polymyxin; nisin; lysozyme; aerogels; delivery systems.

Abbreviations: ABTS, 2,2'-azino-bis(3-ethyl-benzothiazoline-6-sulphonic acid); CFU, colony forming unit; CNF, cellulose nanofibrillated; DS, delivery system; EOLFG, enzymatically oxidized lyophilized fenugreek gum; EOLGG, enzymatically oxidized lyophilized guar gum; EOLSG, enzymatically oxidized lyophilized sesbania gum; FG, fenugreek gum; GG, guar gum; GO, galactose oxidase; Lcc, laccase; LFG, lyophilized fenugreek gum; LGG, lyophilized guar gum; LMS, laccase mediator system; LSG, lyophilized sesbania gum; MIP, mercury intrusion 


\section{Introduction}

Galactomannans (GM) from leguminous plants are widely exploited to generate a considerable range of derivatives with several practical applications. GM are high molecular weight polysaccharides found in the seed endosperms of some Leguminosae (belonging to the family $\underline{\text { Fabaceae) }}$ where they serve as reserve source for carbon and energy upon germination (Prajapati et al., 2013). They have a branched polymeric structure composed of a backbone of mannose units linked by $\beta-1,4$ glycosidic bonds with side units of galactose bound to mannose by $\alpha-1,6$ glycosidic bonds. The average ratio of galactose to mannose (Gal: Man) is variable, depending on the plant species, and ranges from 1:4.5 in cassia (Cassia tora) to 1:1 in fenugreek (Trigonella foenumgraecum) (Crescenzi et al., 2004; Daas, Schols \& de Jongh, 2000; Daas, Grolle, van Vliet, Schols \& de Jongh, 2002; Daniel, Whistler, Voragen \& Pilnik, 1994; Liyanage, Abidia, Auldb \& Moussa, 2015; McCleary, Clark, Dea \& Rees, 1985; Merlini, Boccia, Mendichi \& Galante, 2015; Sittikijyothin, Torres \& Gonçalves, 2005; Wei et al., 2015). The species-dependent monomers ratio makes them, to various extents, soluble in water at different temperatures, chemically/biochemically quite reactive and flexible in application (Cheng, Prud'homme, Chick \& Rau, 2002).

GM and their derivatives are used as rheology modifiers, thickening and suspending agents in food, feed and manufacturing industries (Mathur, 2011). They find application as excipients and coformulants in the biomedical field, such as in pharmaceutical formulations of tablets and in orally controlled drug delivery systems (ODDS), but also as binders, disintegrants, suspending, thickening, gelling, stabilizing and protective agents, to add cohesiveness to drug powder, as they are susceptible to microbial degradation in the large intestine (Meghwa \& Goswami, 2012). GM are also increasingly consumed as dietary fibers with atoxic bioactivities, to lower calories intake and for weight reduction, to control blood glucose, cholesterol and insulin levels, to reduce the risks of heart diseases and colon cancer, as texture modifiers and stabilizers in "specialty" foods (Murthy, Moorthy, Prabhu \& Puri, 2010).

In the present paper, we describe the production of aerogels from enzymatically-oxidized, lyophilized (EOL) sesbania and guar gums, following a protocol similar to the one previously reported for fenugreek gum by Rossi et al. (2016). They are referred to as: EOLSG (for sesbania gum), EOLGG (for guar gum) and EOLFG (for fenugreek gum). Because of their biodegradability, biocompatibility, high surface area and porosities with open pore structures, nanostructured aerogels, particularly from polysaccharides (e.g., starch, cellulose, alginates), constitute an emerging platform as "delivery systems" (DS) of active principles, such as drugs, peptides and enzymes (Ulker \& Erkey, 2014). However, to our knowledge, GM-based aerogels DS have not yet 
been reported by others. We have absorbed into these GM aerogels the following model actives from aqueous solutions: the antibiotic polymyxin B; the antimicrobial peptide nisin; the enzymes lysozyme, protease and lipase, followed in all cases by repeated cycles of water rinsing, to eliminate surface-absorbed compounds, dry blotting and re-lyophilization of the hydrogels to generate "loaded" aerogels. The gradual release of the incorporated actives was monitored either my measuring enzyme activity in solution or in Petri dish on agar culture medium, seeded with different bacterial strains, by evaluating the inhibition halo of cell growth.

Polymyxins, a group of polypeptide antibiotics that consists of 5 chemically different compounds (polymyxins A-E), are secondary metabolites produced by the soil bacterium Paenibacillus polymyxa, were discovered in 1947 (Velkov, Thompson, Nation, \& Li, 2010), but only polymyxin B (PMB) and polymyxin E (colistin) have been used in clinical practice (Payne, Gwinn, Holmes \& Pompliano, 2007; Talbot et al., 2006). They share a common primary sequence of a cationic cyclic decapeptide linked to a fatty acid chain through an alfa-amide linkage (Li, Rayner \& Nation, 2007), with a molecular weight of $1,750 \mathrm{Da}$, the only difference being at position 6 , which is occupied by D-Phe in PMB and D-Leu in colistin. Polymyxins have been used against Gram-negative bacteria responsible for nosocomial infections until the early seventies when they were abandoned, because of their human nephro- and neuro-toxicity. More recently, there has been a revival of interest in polymyxins considering the emergence of multidrug resistant (MDR) Gram-negative bacteria to almost all classes of antibiotics. Polymyxin B is active against MDR bacteria, such as Pseudomonas aeruginosa, Acinetobacter baumannii and Klebsiella pneumonia, also called "superbugs" (Falagas, Kasiakou \& Saravolatz, 2005; Velkov et al., 2010). Thus, innovative, biocompatible, polysaccharide-derived DS could contribute to a more rational and controlled clinical management of PMB. We have absorbed polymyxin B from an aqueous solution unto plugs carved from wafers of EOLFG, EOLSG and EOLGG, followed by rinsing and re-lyophilization to form "loaded" aerogel plugs and shown its release based on the inhibition halo of cell growth of: $P$. aeruginosa, Serratia marcescens, Escherichia coli, Salmonella enterica serovar Typhimurium, Hafnia alvei, Enterobacter cloacae. Controls, i.e., non "loaded" aerogel plugs, had no effect on cell proliferation, while a positive control of free PMB was always present in a separate well of each experimental Petri dish.

Nisin is a natural antimicrobial peptide produced by Lactococcus lactis, composed of 34 amino acids, some of which have a D rather than L configuration (de Arauz, Jozala, Mazzola, \& Penna, 2009). It inhibits Gram-positive bacteria belonging to genera such as: Lactococcus, Streptococcus, Staphylococcus, Micrococcus, Pediococcus, Lactobacillus, Listeria and Mycobacterium, and also vegetative cells and spores of Bacillus and Clostridium (Sahl, Jack, \& Bierbaum, 1995). If 
143 combined with a chelating agent (such as EDTA), nisin is able to destabilize the bacterial outer 144 membrane (Vaara, 1992), thus can also be effective against Gram-negative bacteria like E. coli and 145 P. aeruginosa (Boziaris \& Adams, 1999; Fang \& Tsai, 2003). In 2006, the European Food Safety 146 Authority approved the use of nisin as an antimicrobial food additive (E234). Currently in the EU, 147 the use of nisin is allowed in: semolina and tapioca puddings, in ripened and processed cheese, in 148 clotted cream, mascarpone and pasteurized liquid egg products, at concentrations ranging from 3 to $14912.5 \mathrm{mg} / \mathrm{L}(2010 / 69 / \mathrm{EU})$. It is also used in combination with antibiotics to prevent nosocomial 150 infections caused by drug-resistant bacteria (Tong et al., 2014). A control release of nisin into the 151 medium could contribute to its long term stability and effectiveness. Following the same protocol as 152 with PMB, described in details in Methods, release of nisin from the three aerogels was evaluated 153 on culture agar Petri dish from the growth inhibition of the Gram-positive Enterococcus faecalis 154 and Clostridium tyrobutyricum, the latter under anaerobic conditions.

155 Finally, a few enzymes were also studied for absorption and release from the three GM aerogels. 156 Indeed, enzymes often show low stability in industrial applications under storage or use conditions, 157 and in free form can lead to sensitization and allergies of operators and users. Three different 158 commercial enzymes of great practical importance were selected: egg lysozyme, a commercial 159 protease and a lipase.

160 Lysozyme (LSZ, EC 3.2.1.17) is a hydrolytic enzyme obtained from hen's egg white (HEW), 161 composed of 129 amino acids and with muraminidase activity (Silvetti et al., 2010). It has the 162 ability to hydrolyze the $\beta$-1,4-glycosidic bond between $\mathrm{N}$-acetyl-muramic acid and $\mathrm{N}$-acetyl163 glucosamine in the peptidoglycans of Gram-positive bacteria (Brasca et al., 2013). It is active on 164 bacterial species, such as: Staphylococcus aureus, Micrococcus lysodeikticus, Listeria 165 monocytogenes and L. innocua, Bacillus cereus and B. stearothermophilus, Clostridium 166 thermosaccarolyticum and C. tyrobutyricum, etc. (Ávila, Gómez-Torres, Hernández \& Garde, 2014; 167 Takahashi et al., 2011). Lysozyme is non-toxic to humans and is authorized by EU legislation (EU 168 No. 1129/2011) as a food additive (E1105) at "quantum satis" in ripened cheeses and milk products 169 to prevent butyric acid fermentation which causes the "late blowing" of cheese wheels (Brasca et 170 al., 2013).

171 Proteases constitute a fundamental group of hydrolytic enzymes, mainly employed as detergent 172 additives, but also in several other applications. (Fu et al., 2015; Gupta, Beg \& Lorenz, 2002; Karn 173 \& Kumar, 2015; Souza et al., 2015). Proteases can be unstable, as they are prone to autolysis (thus 174 they are commercially formulated in high-glycol containing gels and reversibly inhibited with boron 175 salts, whose toxicology is however under scrutiny, see TOXICOLOGICAL PROFILE FOR 176 BORON; U.S. DEPARTMENT OF HEALTH AND HUMAN SERVICES; Public Health Service 
Agency for Toxic Substances and Disease Registry; November 2010). Alternatives to boron are widely sought to be used as reversible protease inhibitors. Not least, protease dust inhalation can lead to irritation and pulmonary harm in humans, such as workers and users.

Lipases are increasingly used for natural fat degradation, esterification, transesterification and in the production of high value compounds, such as biopolymers, biodiesel, enantiopure pharmaceuticals, flavors and agrochemicals (Borrelli \& Trono, 2015; Jaeger \& Eggert, 2002; Reetz, 2002;). It would thus be valuable, for both basic studies and applications, to have a readily available, pure and stable lipase entrapped and released from a solid support before use.

Therefore, a great deal of research has been performed on the encapsulation or immobilization of hydrolytic enzymes, e.g.: in gel beads (Verma, Puri \& Barrow, 2015) and nanoparticles (Lin, Chen \& Liu, 2016; Vaghari et al., 2016;) to improve their long term stability against inactivation.

In this work, we describe the absorption, retention and release in active form of lysozyme, protease and lipase from GM aerogel plugs. Released lysozyme activity was demonstrated microbiologically by actual growth inhibition of $C$. tyrobutyricum (i.e., whose vegetative cells and spores represent its target when added to milk during cheesemaking) under anaerobic conditions. Protease and lipase release from similarly "loaded" and re-lyophilized aerogel plugs was estimated from the increase in their respective enzymatic activity, as a function of time, of solutions in which the plugs were incubated.

To better characterize these materials, compressive tests were also performed and their porosity was determined by $\mathrm{Hg}$ absorption under high pressure.

From all of the above, we suggest that aerogels made from enzymatically oxidized and lyophilized GM from leguminous plants, could represent very innovative, versatile, biocompatible delivery systems of various active principles, with potential applications in the biomedical field, as well as in food packaging, feed and industrial products.

\section{Materials and Methods}

\subsection{Materials}

Laccase from Trametes versicolor, in powder form, was a generous gift of Amano Ltd, UK, and Amano, Japan, with a measured activity of $1600 \mathrm{U} / \mathrm{g}$ on ABTS as substrate. It was dissolved with mild stirring in MilliQ water.

The strains of E. coli (ATCC 8739) and S. Typhimurium (ATCC 14028) were from the American Type Culture Collection (U.S.A.). The other strains were obtained from the bacterial collection of the ISPA-CNR (Institute of Science of Food Production of the Italian National Research Council, Milan, 
211 Italy) and included: the Gram-positive C. tyrobutyricum (IN15b) and E. faecalis (VS485); the Gram212 negative P. aeruginosa (PS20), S. marcescens (S91), H. alvei (PS58) and E. cloacae (PS25). All 213 these strains were isolated from contaminated dairy samples, identified through partial 16S rRNA 214 sequencing using the universal primer set p8FPL and p806R (McCabe, Zhang, Khan, Mason \& 215 McCabe, 1995). The Gram-negative strains were also subjected to rpoB sequencing (Sajben, 216 Manczingera, Nagyb, Kredicsa \& Vágvölgyia, 2011). Sequences were analyzed by NCBI BLAST 217 search (http://www.ncbi.nlm.nih.gov/BLAST, Altschul, Gish, Miller, Myers \& Lipman, 1990).

218 Lysozyme hydrochloride was supplied by Sacco (Cadorago (CO), Italy). Nisin (with a potency of $10^{6}$ $219 \mathrm{IU} / \mathrm{g}$ ) and polymyxin B were purchased from Sigma-Aldrich (St. Louis, MO, USA).

220 The industrial protease (Deterzyme® APY 560 in granular from Bacillus alcalophicus) was from 221 Enmex (Tlalnepantla, Mexico). As for the lipase, preliminary experiments were performed with the 222 Type VII enzyme from Candida rugosa (Sigma lot 107H1024) in powder form and later with the 223 commercial lipase (Greasex ${ }^{\circledR}$ Ultra L from Candida lipolitica) in liquid form (from Novozymes, 224 Bagsvaerd, DK).

225 TEMPO and all other chemicals were from Sigma-Aldrich or Fluka.

\subsection{Laccase assay.}

Laccase activity was determined using as substrate $2.48 \mathrm{mM}$ ABTS in $100 \mathrm{mM}$ sodium acetate at $\mathrm{pH}$ 5 (Niku-Paavola, Karhunen, Salola \& Raunio et al., 1988).

230 One laccase unit is defined as the amount of enzyme that catalyzes the oxidation of one $\mu$ mole of $231 \quad$ ABTS in one min at $25^{\circ} \mathrm{C}$ and $\mathrm{pH} 5$.

\subsection{Purification and viscosity measurements of GM solutions.}

234 Non purified gum powder from guar (GG), sesbania (SG) and fenugreek (FG), with a Brookfield viscosity at $1 \%(\mathrm{w} / \mathrm{v})$ in aqueous solution at $20 \mathrm{rpm}$ and $25^{\circ} \mathrm{C}$ of 5000,3000 and $1500-2500 \mathrm{mPa}^{*} \mathrm{~s}$, respectively, were from a commercial source and kindly supplied by Lamberti S.p.A. Actual GM content of unpurified gum varied between 76 and $80 \%(\mathrm{w} / \mathrm{w})$, the remaining components being residual aleuronic proteins, seed coat residues, low mol wt sugars, ashes. Before performing oxidation and other experiments, all GM were purified by dispersion (at 10\% w/w) in a 3:7 solution of $\mathrm{H}_{2} \mathrm{O}$ /ethanol, by stirring at room temperature for $30 \mathrm{~min}$, followed by vacuum filtration. The recovered GM were dispersed (at 10\% w/w) in acetone, stirred as before, and finally recovered by vacuum filtration. Before use, they were oven-dried at $60^{\circ} \mathrm{C}$ overnight. Polysaccharide yield of this procedure was $85-90 \%(\mathrm{w} / \mathrm{w})$, while the residual 10-15\%, composed of proteins and other minor components, was discarded. 
"Purified" GG and FG were dissolved in MilliQ water at room temperature at 1200 rpm with an

246 IKA overhead stirrer for $30 \mathrm{~min}$. SG was firstly dispersed using an IKA Ultraturrax in MilliQ water at room temperature for a min and finally at $1200 \mathrm{rpm}$ with an IKA overhead stirrer for $30 \mathrm{~min}$. The solution was kept standing overnight at room temperature without stirring before any further manipulation. Compared to "non purified" GM, viscosity increased by about $10-15 \%$ at equal gum concentration in water, indicating a higher polymer amount in the "purified" material. GM solutions

251 for all experiments were prepared the same way.

252 Viscosity measurements were performed in a volume of 300-400 $\mathrm{ml}$ in a beaker at room temperature using a Brookfield DV-I Prime, at 20 rpm, mounted with the appropriate spindle.

\subsection{Preparation of the aerogels.}

TEMPO-mediated, laccase oxidation of FG, SG and GG was carried out following the procedure previously described by Merlini et al. (2015) with slight modifications. Purified FG, SG and GG were dissolved, as described in $\S 2.3$, at $1.075 \%(\mathrm{w} / \mathrm{w})$ in $100 \mathrm{ml}$ of MilliQ water at room temperature for $30 \mathrm{~min}$ and the solution was kept standing overnight at room temperature. The mediator TEMPO was added to a final concentration of $0.64 \mathrm{mM}(10 \mathrm{mg})$; laccase, $160 \mathrm{U} / \mathrm{g}$ (GM) (eq. to about $110 \mathrm{mg}$ ), was dissolved in $2 \mathrm{ml}$ of MilliQ water, centrifuged for $4 \mathrm{~min}$ at $4000 \mathrm{rpm}$ and the supernatant added to the solution. The reaction was continued for $3 \mathrm{~h}$ at $35^{\circ} \mathrm{C}$, with constant mechanical stirring at $500 \mathrm{rpm}$, after which Brookfield viscosity was measured and the mixture was left standing at room temperature. Viscosity was measured again after 6 and $24 \mathrm{~h}$ from the start of the reaction.

266 To obtain the aerogels, whole preparations of enzymatically oxidized FG, SG or GG hydrogels were distributed either into 24 well plates, to obtain 16-20 x 12-16 mm cylindrically shaped samples (see also Rossi et al., 2016), or in Petri dishes $(90 \times 12 \mathrm{~mm})$, to give a flat, round aerogel wafer of about $80 \times 5 \mathrm{~mm}$, and frozen for $12 \mathrm{~h}$ at $-80^{\circ} \mathrm{C}$, followed by freeze-drying at $-55^{\circ} \mathrm{C}$ for $48 \mathrm{~h}$ (these materials are referred to as EOLFG, EOLSG and EOLGG, respectively).

\subsection{Preparation of actives solutions.}

273 A $1 \mathrm{~g} / \mathrm{L}$ of polymyxin B stock solution was prepared in sterile distilled water, filter-sterilized and stored at $4^{\circ} \mathrm{C}$. A working solution of $300 \mathrm{mg} / \mathrm{L}$ was prepared by diluting the stock solution in distilled, sterile water. Nisin working solution $(50,000 \mathrm{IU} / \mathrm{ml})$ was prepared by dissolving the appropriate amounts of powder in sterile $0.02 \mathrm{~N} \mathrm{HCl}$, sterilized by filtration through a $0.20 \mu \mathrm{m}$ membrane filter (Corning, USA) and stored at $4{ }^{\circ} \mathrm{C}$. Lysozyme powder was dissolved in distilled, sterile water to give a stock solution of $2 \mathrm{~g} / \mathrm{L}$, which was freshly prepared before each set of 
experiments and filter-sterilized as before. A lysozyme working solution of $1.25 \mathrm{~g} / \mathrm{L}$ was prepared by 280 diluting the stock solution with distilled, sterile water.

281 Before use, $100 \mathrm{mg}$ of protease were dissolved in $1 \mathrm{ml}$ of MilliQ water and centrifuged at 11,200 x g at RT for $5 \mathrm{~min}$, to eliminate insoluble material present in the formulation, the pellet was discarded and the "loading" experiments were carried out with the supernatant.

In the case of lipase, $125 \mathrm{mg}$ of the C. rugosa lipase in powder form were likewise dissolved in $1 \mathrm{ml}$ of MilliQ water and centrifuged at $11,200 \mathrm{x} \mathrm{g}$ at RT for $5 \mathrm{~min}$, the pellet was discarded and the supernatant used for "loading" experiments. The commercial lipase from C. lipolitica, in liquid form, was used as such.

Protein concentration was measured by the Bradford assay (Bradford, 1976) and turned out to be: $33 \mathrm{mg} / \mathrm{g}$ for the protease, about $5 \mathrm{mg} / \mathrm{g}$ for the C. rugosa lipase and $23 \mathrm{mg} / \mathrm{ml}$ for the C. lipolitica lipase.

\subsection{Absorption of the active principles in the aerogels.}

293 Plugs (Ø $8 \mathrm{~mm}$ ) of EOLFG (from fenugreek gum), EOLSG (from sesbania gum) and EOLGG (from guar gum) were carved with a cork borer as described by Rossi et al. (2016). Polymyxim B, nisin, lysozyme, protease or lipase were absorbed unto the aerogels by immersing one to three plugs for $1 \mathrm{~h}$ at room temperature in an Eppendorf tube containing 0.5-1.0 $\mathrm{ml}$ of solution of active at a specified concentration. The plugs were then rinsed three times in $1 \mathrm{ml}$ of distilled, sterile water and blotted on UV-sterilized filter paper to remove eventual active solution present on the surface. The "theoretical" amount of active absorbed was calculated from the weight difference of the plug(s) (initial weight: 7$9 \mathrm{mg}$ ), measured on each plug before and after immersion in solution, which gave an average weight increase of 13-15-fold.

Protease and lipase protein concentration in the incubation solutions were further checked with the Bradford assay, before and after absorption of the enzymes as explained above, and found to be equal. In all cases, the "loaded" hydrogels were re-lyophilized in order to obtain the corresponding "loaded" aerogels to be tested.

306 The effect of lyophilization on lipase and protease was evaluated by measuring specific activity of 307 both enzymes after freeze-drying of their respective aqueous solutions, re-dissolution in water and was negligible.

\subsection{Bacterial strains and culture conditions}

311 All bacterial strains were routinely grown under standard conditions. Working cultures of $P$. aeruginosa, S. marcescens, E. coli, S. Typhimurium, H. alvei and E. cloacae were propagated in 
313 Brain Heart Infusion broth (Scharlau Microbiology, Barcelona, Spain) and incubated at $30{ }^{\circ} \mathrm{C}$ (at 37

$314{ }^{\circ} \mathrm{C}$ for $E$. coli and $S$. Typhimurium) for 18 h. C. tyrobutyricum was cultured anaerobically 315 (Anaerocult A Merck, Darmstadt, Germany) in Reinforced Clostridial Medium (VWR Chemical, 316 Leuven) at $37{ }^{\circ} \mathrm{C}$ for 48 h. E. faecalis was grown aerobically in M17 broth (Biolife Italiana, Milano, 317 Italy) at $37{ }^{\circ} \mathrm{C}$ for $18 \mathrm{~h}$. Before each set of experiments, all enriched cultures were diluted in Ringer 318 solution (Scharlau Microbiology) to reach a concentration of $10^{5} \mathrm{CFU} / \mathrm{ml}$. For solid media, $15 \mathrm{~g} / \mathrm{L}$ 319 agar (Scharlau Microbiology) was added to the broth before sterilization.

\subsection{Evaluation of release and activity of active principles}

322 The detection of polymyxin B, nisin and lysozyme released from the aerogels was assessed by a modified method described by Rossi et al. (2016). For anti-bacterial activity, the poured plate method was used. Briefly, each Petri dish was layered with a selective agar medium, seeded with the bacterial inoculum at a concentration of $10^{5} \mathrm{CFU} / \mathrm{ml}$. After solidification of the agar, equidistant wells $(\varnothing 8$ $\mathrm{mm}$ ) were carved with a sterilized cork borer and filled with: i) different concentrations of the free active; ii) plugs of "loaded" EOLFG, EOLSG or EOLGG containing the appropriate amount of active; iii) a control of "unloaded" EOLFG, EOLSG or EOLGG plug. Inoculated plates were incubated at $30{ }^{\circ} \mathrm{C}$, or $37{ }^{\circ} \mathrm{C}$ in the case of E. coli, S. Typhimurium and C. tyrobutyricum, for $24 \mathrm{~h}$. Release of actives from aerogels was evaluated from the inhibition halo zones formed around each well in comparison to the control aerogel and to the diffusion of the free active substance. All manual operations were performed under a vertical laminar flow hood in sterile conditions and experiments were run in duplicate.

Release of protease or lipase in water was evaluated by withdrawing aliquots of the incubation solution and determining enzyme activity.

Proteolytic activity was calculated from the increase in absorbancy at $440 \mathrm{~nm}$ in a $1.0 \mathrm{ml}$ reaction volume composed of $0.25 \% \mathrm{w} / \mathrm{v}$ azocasein, $0.3 \mathrm{mM}$ calcium chloride, $25 \mathrm{mM}$ Trizma base (pH 8) for $10 \mathrm{~min}$ at $40^{\circ} \mathrm{C}$. The reaction was stopped by adding $1.0 \mathrm{ml}$ of $20 \%$ trichloroacetic acid, followed by centrifugation at $11,200 \mathrm{x} \mathrm{g}$ at $\mathrm{RT}$ for $5 \mathrm{~min}$. Protease activity is expressed as $\Delta$ O.D. at $440 \mathrm{~nm} / 10$ $\mathrm{min} / \mathrm{ml}$ and one Unit of protease activity is the amount of enzyme causing a $\Delta$ O.D of 1.0 under those conditions.

Lipolytic activity was determined by measuring initial linear absorbance increase at $410 \mathrm{~nm}$ produced by p-nitrophenol upon hydrolysis of $1 \mathrm{mM}$ p-nitrophenyl laurate (dissolved in isopropanol) in $10 \mathrm{mM}$ ammonium acetate $\mathrm{pH} 7.2$ and $0.5 \%$ Triton X-100, in $1.0 \mathrm{ml}$ reaction volume (Santambrogio et al., 2013). Lipase activity is expressed as $\Delta$ O.D. at $410 \mathrm{~nm} / \mathrm{min} / \mathrm{ml}$ and one Unit of lipase activity is the amount of enzyme causing a $\Delta$ O.D of 1.0 under those conditions. 
All measurements were performed in triplicate.

\subsection{Determination of pore size}

352 Total porosity, average and modal pore size, pore size distribution, and bulk density of the aerogels 353 were measured by mercury intrusion porosimetry (MIP), which consists in forcing mercury into the 354 sample pores at increasing pressures. The output data is the volume of mercury intruded into the 355 sample as a function of the pressure applied, which is inversely proportional to the pores size 356 (Santos et al., 2015). Pascal 140 coupled with Pascal 240 porosimeters (Thermo Fisher Scientific, 357 Waltham, MA) were used for the analysis. Pascal 140 module allows to reach low pressures (up to $358400 \mathrm{kPa}$ ), thereby measuring only large pores (macropores). Pascal 240 reaches pressures up to 200 $359 \mathrm{MPa}$, thus allowing measurement of the porosity into the mesopore region. Cylindrical aerogel 360 corks weighing $40 \pm 3 \mathrm{mg}$ were used in the analyses. To overcome the potential limitations 361 associated to MIP (Majda et al., 2016) freeze-dried samples were placed in a dessicator containing $362 \mathrm{CaCl}_{2}$ for 3 weeks to remove residual moisture. The residual moisture content measured with a 363 moisture analyzer HB43-S (Mettler Toledo, Greifensee, Switzerland) was as low as $0.5 \pm 0.02 \%$. 364 During analysis, air inside the samples was removed by three degassing cycles. Mercury intrusion 365 was performed according to the PASCAL (Pressurization with Automatic Speed-up by Continuous 366 Adjustment Logic) system, which minimizes crushes and deformations of the samples. Pore 367 diameter was calculated according to the Washburn equation (Washburn, 1921) assuming a 368 cylindrical shape of the pores (Webb and Orr, 1997), as in (1):

$$
P=-2 \sigma \cos \frac{\theta}{r}
$$

370 where $P$ is the applied pressure, $r$ is the radius of the pore, $\sigma$ is the surface tension of the mercury 371 and $\theta$ is the contact angle between mercury and polymer. A surface tension of $480 \mathrm{mN} / \mathrm{m}$ and a 372 contact angle of $140^{\circ}$ (Kim \& Chu, 2000; Joshi et al., 2015) were used for all measurements. 373 SOL.I.D (SOLver of Intrusion Data) software was used for data elaboration.

\subsection{Determination of mechanical features.}

376 Cylindrically shaped samples ( 20 mm height $\times 10 \mathrm{~mm}$ diameter $)$ of both pristine non-oxidized, 377 lyophilized gums (LFG, LSG, and LGG) and the corresponding laccase-oxidized, lyophilized 378 aerogels (EOLFG, EOLSG, and EOLGG) were evaluated by a compressive test according to the procedure described by Deszczynski, Kasapis \& Mitchell (2003) and more recently applied by 
380 Rossi et al. (2016). Briefly, two consecutive cycles of compression were performed with a 381 dynamometer (mod. Z005, Zwick Roell, Ulm, Germany) fitted with a $100 \mathrm{~N}$ load cell and 382 connected to two plates (30 mm diameter), placed at a distance of $22 \mathrm{~mm}$ apart. Each compression 383 cycle accounted for a maximum deformation of the sample of $2 \mathrm{~mm}$, at a crosshead speed of $2 \mathrm{~mm}$ $384 \mathrm{x} \mathrm{s}^{-1}$. Stress-strain and force-time plots allowed for the calculation of compressive modulus, 385 maximum compressive force, cohesiveness, springiness, and resilience using the software 386 TestXpert V10.11 Master (see also Ghafar et al., 2015). All tests were carried out at $23 \pm 0.5{ }^{\circ} \mathrm{C}$ and $38740 \pm 2.5 \%$ relative humidity $(\mathrm{RH})$. At least ten replicates were performed with each sample. 388 Statistical differences between mean values were determined by Student's $t$-test, with a significance level $(p)<0.05$, using Statgraphic Plus 4.0 software.

\section{Results and Discussion}

\subsection{Release from aerogels and activity of polymyxin B against Gram-negative bacteria.}

The properties of EOLFG, EOLSG and EOLGG aerogels as delivery systems were firstly investigated with the antibiotic polymyxin B against six Gram-negative bacterial strains. All the six bacterial species selected are responsible for nosocomial infections. Indeed, $P$. aeruginosa is one of the major multidrug-resistant (MDR) bacterial species and almost all the currently available antibiotics have no effect on it, with the exception of polymyxins (Velkov et al., 2010). Therefore, since the mid nineties, the use of polymyxins has seen a renewed interest, in spite of their suspected nephrotoxicity and neurotoxicity. Thanks to the wide activity spectrum of polymyxin $\mathrm{B}$, we were able to test five other bacterial species of Enterobacteriaceae, namely: S. marcescens, E. coli, S. Typhimurium, H. alvei and E. cloacae; all responsible for nosocomial infections that can lead to lifethreatening bacteremia (Alexopoulou et al., 2016; Kim et al., 2015; Steinbach, Töpper, Adam, \& Kees, 2015). Fig.1a shows the inhibition zone by polymyxin B released from "loaded" plugs of :EOLFG (2), 409 
a
2

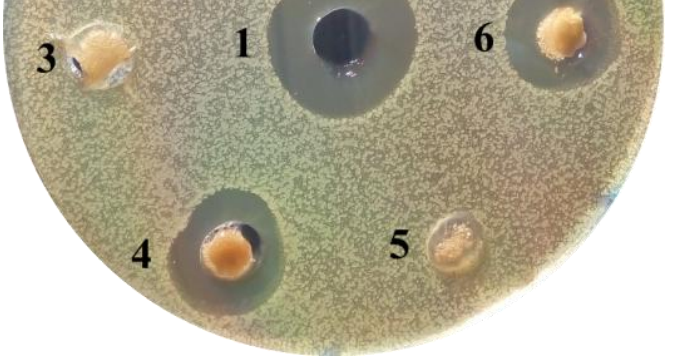

b

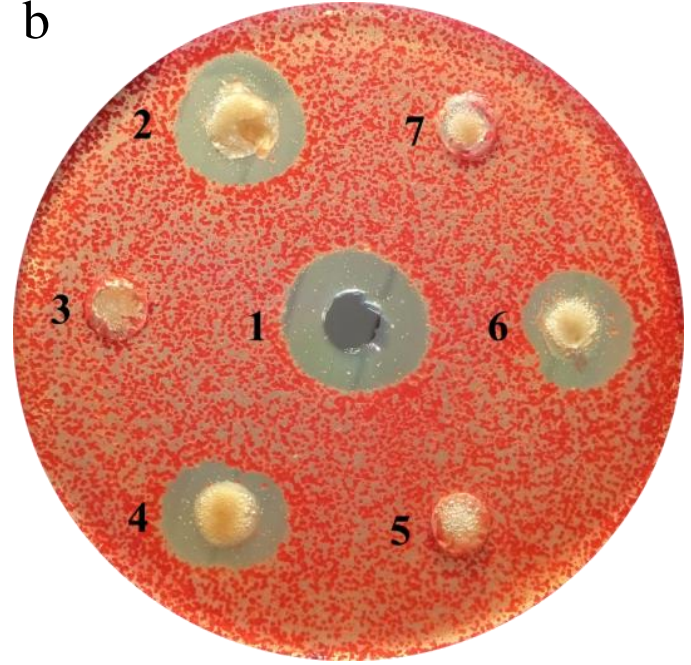

Fig. 1-a,b- Inhibition by polymyxin B released from aerogels of Gram-negative bacterial cell growth. Central well (1), $30 \mu \mathrm{g}$ (equivalent to 22 nanomoles) of free polymyxin B. Lateral wells: plugs of loaded EOLFG (2), control EOLFG (3); loaded EOLSG (4), control EOLSG (5); loaded EOLGG (6), control EOLGG (7). Fig. 1a: P. aeruginosa. Fig. 1b: S. marcescens.

The central well (1) was filled with $100 \mu \mathrm{l}$ of $300 \mathrm{mg} / \mathrm{l}$ of polymyxin B (equivalent to $30 \mu \mathrm{g}$ or 22 nanomoles of active substance). Control plugs of "unloaded": EOLFG (3), EOLSG (5) and EOLGG (7) were fitted in the corresponding wells. The amount of incorporated polymyxin B in aerogel plugs was calculated from the individual average weight increase, performed in triplicate, after $1 \mathrm{~h}$ immersion in a polymyxin B solution, rinsing, blotting, and was estimated to be $28.9 \pm 8.3 \mu \mathrm{g}$ for EOLFG, $23.7 \pm 2.2 \mu \mathrm{g}$ for EOLSG and $32.4 \pm 6.8 \mu \mathrm{g}$ for EOLGG.

As detailed in $\S 2.6$, "loaded" plugs were rinsed three times in water in order to remove any polymyxin B loosely absorbed on the surface of the aerogels. $100 \mathrm{ul}$ of each rinse water was evaluated for cell growth inhibition on a similarly seeded Petri dish. While the first rinse water showed a very slight inhibition halo, the third one had none (see Fig. 1.S in "Supplementary Material"). Therefore, we conclude that the large halos around the plugs of EOLFG, EOLSG and EOLGG in Fig. 1a are largely or exclusively due to the release of polymyxin B absorbed and retained within the aerogels.

A similar experiment was carried out on a strain of $S$. marcescens, a species recognized to cause human clinical diseases, with a multidrug-resistance profile (Zavascki, Goldani, Li \& Nation, 2007). Fig $1 \mathrm{~b}$ shows the inhibition zone by polymyxin B released from "loaded" plugs of: EOLFG (2), EOLSG (4) and EOLGG (6) of S. marcescens cell growth. As for P. aeruginosa, the third rinse water of all plugs developed no halos (see Fig 2.S in "Supplementary Material"). 
436 Following the same protocol as above, we have evaluated four other Gram-negative bacterial 437 species involved in nosocomial infections, that can be fatal, mostly if infected patients are elderly, 438 young, or people with depressed immune systems (Alexopoulou et al., 2016; Kim et al., 2015; 439 Steinbach et al., 2015). The bacterial strains were the following: $S$. Typhimurium (Fig. 1c), E. coli 440 (Fig. 1d), E. cloacae (Fig. 1e) and H. alvei (Fig. 3.S in Supplementary Material). All strains 441 analyzed were susceptible to polymyxin B cell growth inhibition, which was absorbed and released 442 from the aerogel plugs.
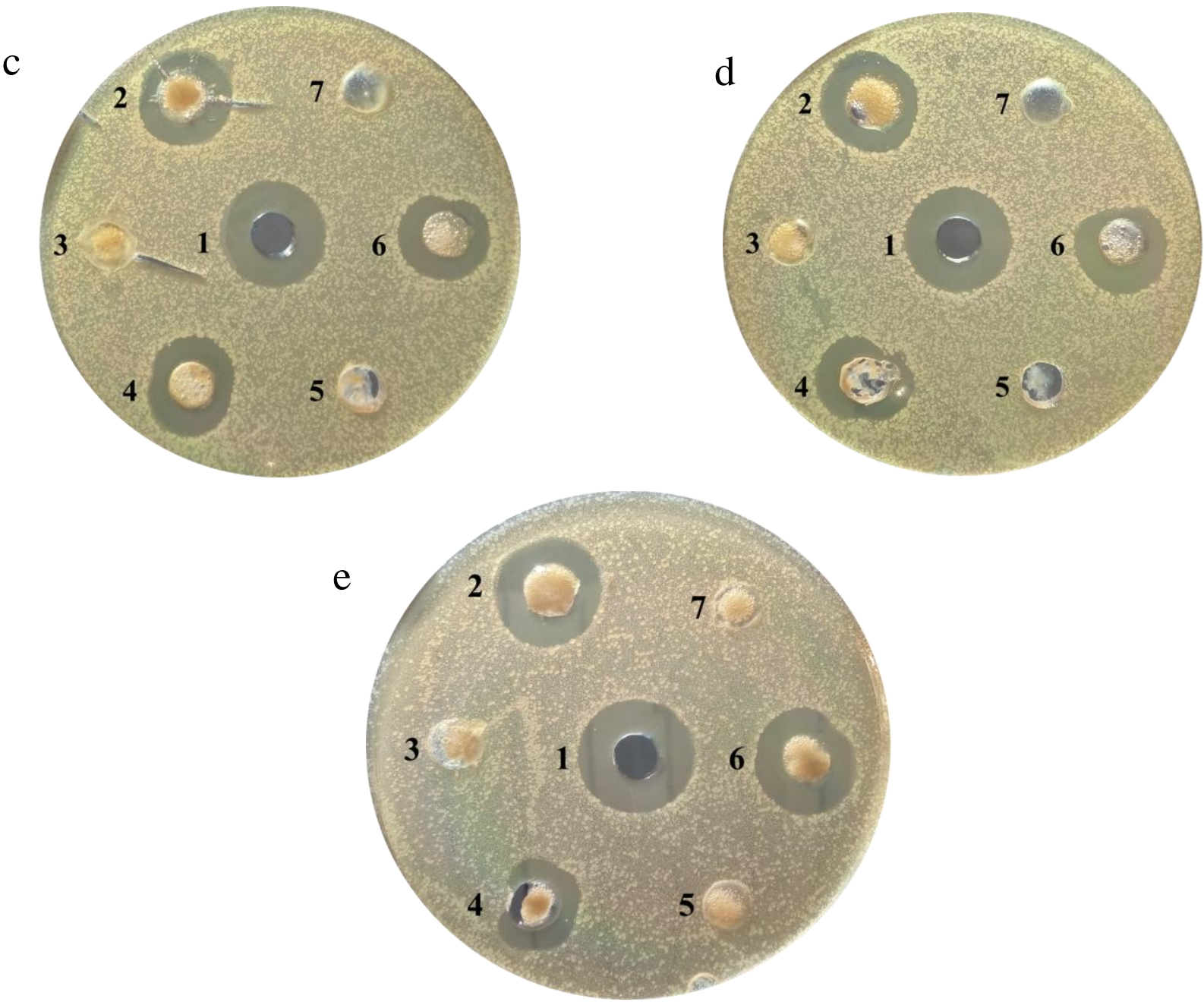

Fig. 1-c-e- Inhibition by polymyxin B released from aerogels of Gram-negative bacterial cell growth. Central well (1), $30 \mu \mathrm{g}$ (equivalent to 22 nanomoles) of free polymyxin B. Lateral wells: plugs of loaded EOLFG (2), control EOLFG (3); loaded EOLSG (4), control EOLSG (5); loaded EOLGG (6), control EOLGG (7). Fig. 1c: S. Typhimurium. Fig. 1d: E. coli. Fig. 1e: E. cloacae. 
It is difficult to make a quantitative evaluation of polymyxin B released from Figs.1, a-e and Fig.

455 3.S. However, by comparing the diameters of the halos around the "loaded" plugs to the central 456 wells filled with the free active substance, the amounts of polymyxin B diffused appear to be fairly 457 equal.

\subsection{Release from aerogels and activity of nisin against Gram-positive bacteria.}

460 The activity of nisin loaded and released from the three GM aerogels was evaluated against Gram461 positive bacteria in a similar way as for polymyxin B.

462 Fig. 2a shows the growth inhibition by nisin released from "loaded" plugs of: EOLFG (2), EOLSG 463 (4) and EOLGG (6) on cells of E. faecalis isolated from contaminated dairy samples and Fig. 2b on 464 a strain of $C$. tyrobutyricum, cultured under anaerobic conditions. The amount of incorporated nisin 465 was calculated from the average weight increase of individual aerogel plugs, performed in triplicate, 466 after $1 \mathrm{~h}$ of immersion in a nisin solution $(50,000 \mathrm{IU} / \mathrm{g})$ and was estimated to be $120.5 \pm 34.6 \mu \mathrm{g}$ for EOLFG, $98.9 \pm 9.3 \mu \mathrm{g}$ for EOLSG and 135.1 $\pm 28.5 \mu \mathrm{g}$ for EOLGG. All plugs were rinsed three times, as before, in order to remove nisin eventually present on the outer surface. The third rinse water did not develop any halo (see Fig. 4.S in "Supplementary Material”).
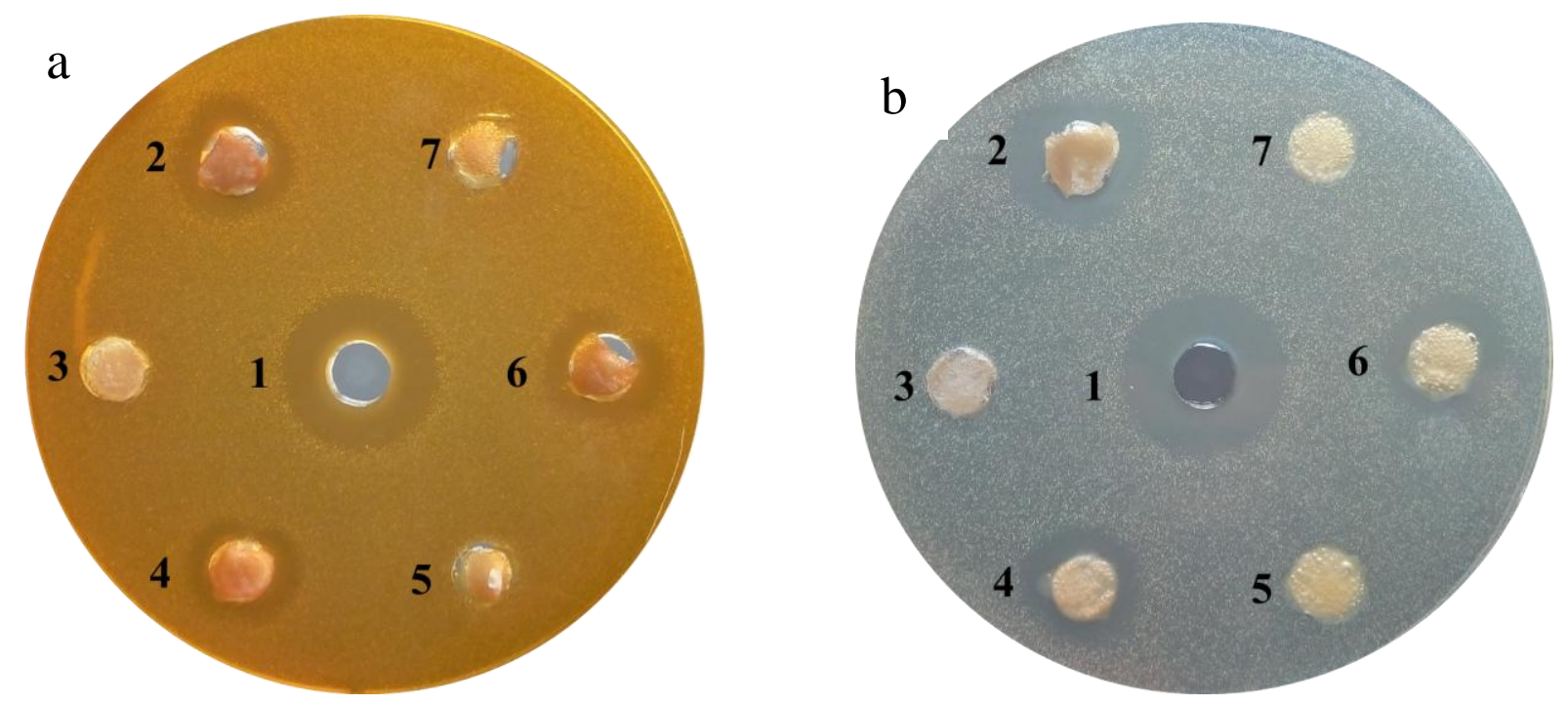

Fig. 2a,b - Inhibition by nisin released from aerogels of Gram-positive bacterial cell growth. Central well (1) $125 \mu \mathrm{g}$ of free nisin (equivalent to 37 nanomoles). Lateral wells: plugs of loaded EOLFG (2), control EOLFG (3); loaded EOLSG (4), control EOLSG (5); loaded EOLGG (6), control EOLGG(7). Fig. 2a: E. faecalis. Fig. 2b: C. tyrobutirycum.

\subsection{Release and activity of lysozyme against C. tyrobutirycum}


479 The muraminidase lysozyme is used in cheese and milk products to prevent butyric acid 480 fermentation prevalently caused by Clostridium species. In a previous work (Rossi et al., 2016) we 481 have described the release of lysozyme from EOLFG aerogel, evaluated by a standard biochemical 482 test, based on the hydrolytic activity of this enzyme on agar plates layered with lyophilized cells of 483 M. lysodeikticus, while in the present work a microbiological test was used.

484 Fig. 5.S shows the inhibition zone by lysozyme released from a "loaded" plug of EOLFG (2) on live 485 cells of $C$. tyrobutirycum, grown under anaerobic conditions. The well on top (1) was filled with 100 $486 \mu \mathrm{l}$ of $1.25 \mathrm{~g} / \mathrm{L}$ of lysozyme (i.e., $125 \mu \mathrm{g}$ of protein equivalent to 8.7 nanomoles of active substance). A 487 control plug of EOLFG (3) was fitted in the corresponding well. The amount of incorporated 488 lysozyme was calculated from the average weight increase of individual aerogels, performed in 489 triplicate, after $1 \mathrm{~h}$ of immersion in a lysozyme solution and was estimated to be $120.5 \pm 34.6 \mu \mathrm{g}$ of 490 lysozyme for EOLFG. Similar experiments with EOLSG and EOLGG gave somewhat unclear 491 results, as those two aerogels turned out to be too brittle under the anaerobic and temperature 492 conditions used for the test. However, this aspect is being investigated.

493 Therefore, it appears that with the three selected antimicrobials and under the experimental 494 conditions applied, the release of active was able to control microbial growth in vitro, even in the 495 presence of a relatively high cell concentration.

\subsection{Uptake and release of protease and lipase from GM aerogels.}

498 The following preliminary controls were performed on the two industrial enzymes tested in order to 499 substantiate our experimental approach:

500 i. The effect of the lyophilization procedure on the lipase and protease was tested by activity determination of the enzymes, before and after lyophilization from water solution and re-

Enzyme release from "loaded" aerogel plugs in water was monitored by measuring protein concentration and increase in enzyme activity as a function of time. 
511 Fig. 3 shows the kinetics of protease release at RT from the three hydrogels, measured every hour, 512 for $6 \mathrm{~h}$, expressed as percentage of the "theoretical" total protease activity loaded. The mean values 513 and standard deviations are reported in Tab. 1.S (see Supplementary Material).

514 Protease release appears to be faster in the first $2 \mathrm{~h}$ and then gradually reaches a plateau after $6 \mathrm{~h}$.

518 Fig. 3 - Time course of protease release in water solution from "loaded" hydrogel plugs of EOLFG, 519 EOLSG and EOLGG. Each time point was performed in triplicate on separately prepared plugs and 520 is expressed as the average percentage of the "theoretical" total protease activity loaded.

522 It can be calculated that this represents, in all three cases, an almost complete release of enzyme loaded into the aerogels (Tab. 1.S.).

524 In the case of lipase, preliminary evaluations were performed with a C. rugosa enzyme obtained from 525 Sigma for research purposes, containing over $90 \%$ of non protein material, which had to be discarded 526 before further experiments. Loading and release were performed only on EOLFG, as described 527 above, and it was found that almost all the calculated amount of enzyme absorbed was released after $5285 \mathrm{~h}$ incubation in water at RT (not shown). However, in consideration of the little amount of enzyme 529 available, the other two aerogels were not tested.

530 Therefore, for practical applications (e.g., in detergency), we considered more meaningful to try with 531 an industrial enzyme commercially available, hence the choice of Novozymes' Greasex Ultra L from 
C. lipolitica with an activity of $15 \mathrm{U} / \mathrm{ml}$, used as such with no further purification or pre-treatments.

533 In this case, as shown in Fig. 6.S for the three aerogels, the release of lipase in solution was limited to 534 about $30 \%$ of the "theoretical" maximum, even after a very long incubation period, as if the stabilizing agents contained in the commercial formulation of this enzyme (e-g., glycols, salts, etc.), prevented or limited its full release. Purification experiments of this lipase are underway to verify the hypothesis, focusing mainly on EOLFG which preserves its structure upon prolonged incubation periods in solution.

539 The mean values and standard deviations of the experimental data points of Fig. 6.S are reported in 540 Tab. 2.S.

\subsection{Determination of aerogels pore size}

543 Data from MIP tests are reported in Tab. 1.

\begin{tabular}{cccccc}
\hline Sample & $\begin{array}{c}\text { Bulk } \\
\text { density } \\
\left(\mathbf{k g ~ x ~ m}^{-3}\right)\end{array}$ & $\begin{array}{c}\text { Porosity } \\
(\%)\end{array}$ & $\begin{array}{c}\text { Pore surface } \\
\text { area } \\
\left(\mathbf{m}^{\mathbf{2}} \mathbf{x ~ g}^{-\mathbf{1}}\right)\end{array}$ & $\begin{array}{c}\text { Average pore } \\
\text { diameter } \\
(\boldsymbol{\mu m})\end{array}$ & $\begin{array}{c}\text { Modal pore } \\
\text { diameter } \\
(\boldsymbol{\mu m})\end{array}$ \\
\hline EOLFG & 35.9 & 99.91 & 11.32 & 9.83 & 42.44 \\
EOLSG & 32.8 & 96.19 & 16.89 & 6.94 & 3.59 \\
EOLGG & 31.3 & 93.28 & 15.54 & 7.68 & 102.71 \\
\hline
\end{tabular}

Tab. 1 - MIP parameters of the three GM aerogels

548 The aerogel from fenugreek (EOLFG) exhibited higher density $\left(35.9 \mathrm{~kg} \mathrm{x} \mathrm{m}^{-3}\right)$ compared to guar 549 gum (EOLGG) and sesbania (EOLSG) with 31.3 and $32.8 \mathrm{~kg} \mathrm{x} \mathrm{m}^{-3}$, respectively. Because a number 550 of parameters may affect the bulk density of aerogels (e.g., type of polymer, initial polymer concentration, $\mathrm{pH}$, ionic strength, air inclusion method, and instrumental technique for the measurements), a strict comparison among different materials is relatively hard to make. For example, sodium carboxymethyl cellulose aerogels were reported to have bulk density of $56.8 \mathrm{~kg} \mathrm{x}$ $\mathrm{m}^{-3}$ (Lin, Li, Lu, \& Cao, 2015), whereas the bulk density of wheat gluten-based aerogels ranged between 58 and $343 \mathrm{~kg} \mathrm{~m}^{-3}$ (Blomfeldt et al., 2010), therefore a wide range of values is to be expected. On the other hand, previously reported open-cell CNF foams and CNF aerogels had densities of 15 and 7-20 $\mathrm{kg} \mathrm{x} \mathrm{m}^{-3}$, respectively (Jiang \& Hsieh, 2014; Svagan, Samir, \& Berglund, 2008), lower than the values we have found, so that different thermal values are to be expected. 
559 From a practical point of view, it is interesting to notice that expanded and extruded polystyrene 560 closed-cell foams, for thermal insulation applications, have densities in the range of $16-45 \mathrm{~kg} \mathrm{x} \mathrm{m}^{-3}$, 561 whereas those of polyurethane are in the range of 40-55 $\mathrm{kg} \mathrm{x} \mathrm{m}^{-3}$ (Al-Homoud, 2005). Thus, it will 562 be interesting to study the thermal insulation properties of the plant-derived materials we have 563 obtained.

564 The three aerogels described in this study showed very high open porosity values, with an 565 outstanding $99.9 \%$ measured for the EOLFG sample. This value is in line with a recent work on 566 lightweight foams based on nano-cellulose, which exhibited an open porosity of 99.6\% (Wicklein et 567 al., 2015). In our studies, differences in pore size and distribution were observed. EOLFG showed 568 pores of larger size compared to the two other aerogels, as demonstrated by both pore surface area $569\left(11.32 \mathrm{~m}^{2} \mathrm{x} \mathrm{g}^{-1}\right)$ and average pore diameter $(9.83 \mu \mathrm{m})$ (see Tab. 1). EOLSG showed the smallest 570 pores, with pore surface area and average diameter of $16.89 \mathrm{~m}^{2} \mathrm{x} \mathrm{g}^{-1}$ and $6.94 \mu \mathrm{m}$, respectively. 571 While EOLGG stood halfway in terms of pore size. There was also a difference in pore size 572 distribution according to the nature of the GM aerogel.

573 As indicated by the modal pore diameter, most of the pores were centered at $\sim 3.6 \mu \mathrm{m}$ diameter for 574 the EOLSG (meaning that the smallest pores are more largely represented), $42 \mu \mathrm{m}$ for EOLFG, and $\sim 103 \mu \mathrm{m}$ for the EOLGG. This can be seen in the pore size distribution plots of Fig. 7, a-c.S (see Supplementary Material). While the pore diameter frequency distribution of the sample of EOLFG (Fig. 7,a.S) includes several classes of the same height between 10 and $50 \mu \mathrm{m}$, the frequency distribution of samples EOLSG (Fig. 7,b.S) and EOLGG (Fig. 7,c.S) is somehow skewed toward high pore diameters. Moreover, with EOLGG and EOLSG the occurrence of a second peak can also be observed, which is broader for EOLSG between 1 and $5 \mu \mathrm{m}$. These results indicate that, 581 although with some differences, all the three aerogels tested in this work had more open macropores than mesopores and micropores in their final structure, suggesting a preferential practical application where rapid capillary suction is of utmost importance, e.g., for "fast" delivery systems 584 and in liquid cleaning/removing devices (Blomfeldt et al., 2010).

585 Finally, Fig. 4 (which is derived from the data of Fig. 7, a-c.S) indicates that in the case of 586 fenugreek there is a wider distribution of pores with intermediate size (20-50 um) than in guar and 587 sesbania, presumably because it is the most extensively cross-linked aerogel. 


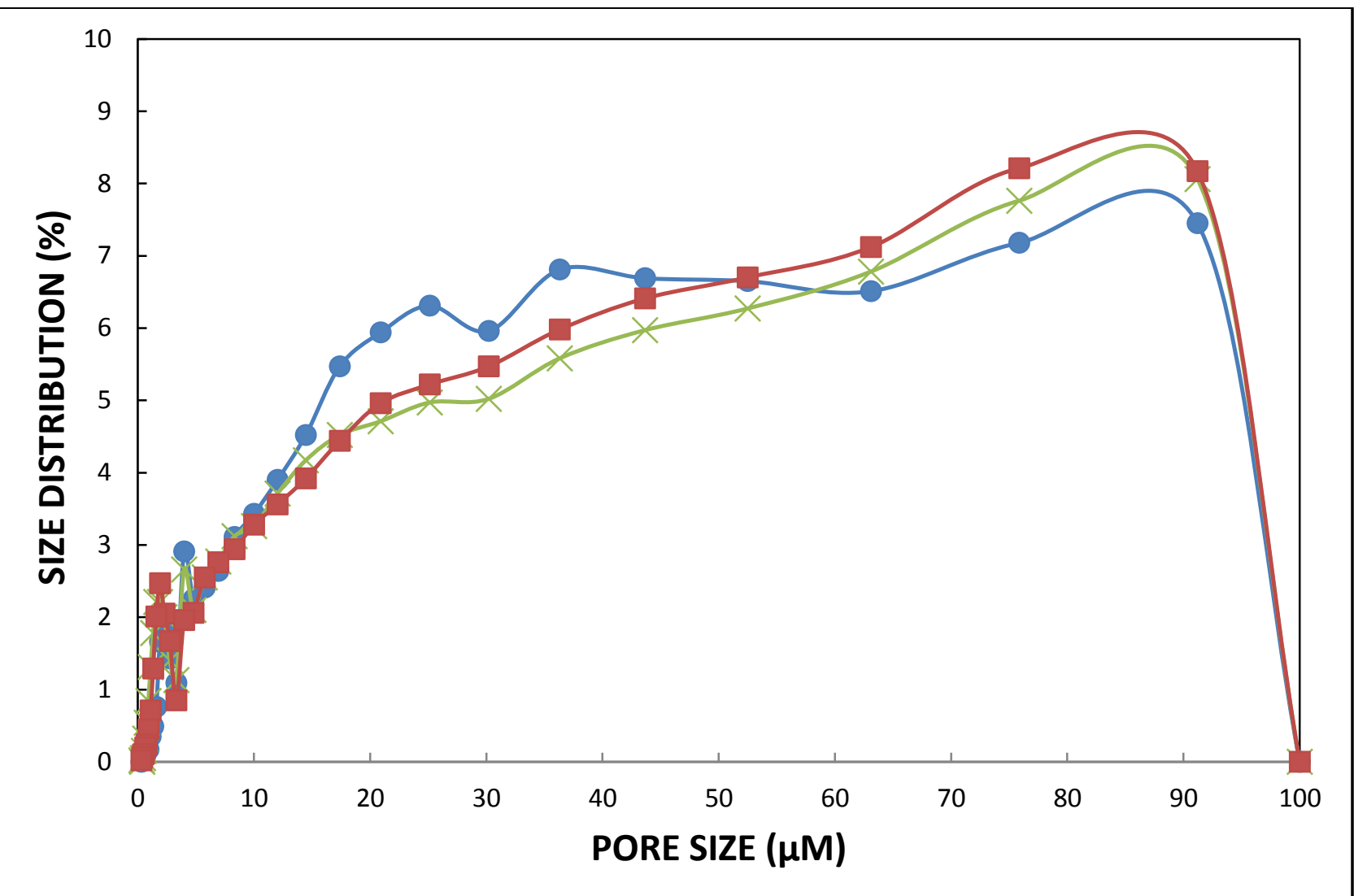

Fig. 4- Pore size distribution in diameter (abscissa) $v s$ their \% distribution (ordinate) of the three

GM aerogels (blu curve $(\bullet)$, EOLFG; green curve (x), EOLSG; red curve (๘), EOLGG.

594 However, if we consider the distribution of larger pores (i.e., between 50-100 $\mu \mathrm{m}$ ), guar appears to have the most, closely followed by sesbania.

\subsection{Mechanical properties}

598 Large deformation tests allowed to quantify the effect of enzymatic oxidation on the mechanical 599 properties of EOLFG, EOLSG and EOLGG. Tab. 2 reports the mechanical parameters obtained 600 from compressive tests.

601

\begin{tabular}{lccccc}
\hline Sample & $\begin{array}{c}\text { E-mod } \\
(\mathbf{k P a})\end{array}$ & $\begin{array}{c}\mathbf{F}_{\max } \\
(\mathbf{N})\end{array}$ & Cohesiveness & Springiness & Resilience \\
\hline LFG & $\begin{array}{c}0.502 \\
( \pm 0.085)^{\mathrm{a}}\end{array}$ & $\begin{array}{c}0.081 \\
( \pm 0.014)^{\mathrm{a}}\end{array}$ & $\begin{array}{c}0.713 \\
( \pm 0.040)^{\mathrm{a}}\end{array}$ & $\begin{array}{c}0.651 \\
( \pm 0.042)^{\mathrm{ab}}\end{array}$ & $\begin{array}{c}0.393 \\
( \pm 0.033)^{\mathrm{ab}}\end{array}$ \\
EOLFG & $\begin{array}{c}22.775 \\
( \pm 5.792)^{\mathrm{b}}\end{array}$ & $\begin{array}{c}2.376 \\
( \pm 0.548)^{\mathrm{b}}\end{array}$ & $\begin{array}{c}0.685 \\
( \pm 0.034)^{\mathrm{a}}\end{array}$ & $\begin{array}{c}0.611 \\
( \pm 0.038)^{\mathrm{a}}\end{array}$ & $\begin{array}{c}0.316 \\
\mathrm{c}\end{array}$
\end{tabular}




\begin{tabular}{lccccc} 
LSG & $\begin{array}{c}0.249 \\
( \pm 0.083)^{\mathrm{a}}\end{array}$ & $\begin{array}{c}0.039 \\
( \pm 0.012)^{\mathrm{a}}\end{array}$ & $\begin{array}{c}0.728 \\
( \pm 0.033)^{\mathrm{a}}\end{array}$ & $\begin{array}{c}0.665 \\
( \pm 0.033)^{\mathrm{b}}\end{array}$ & $\begin{array}{c}0.434 \\
( \pm 0.034)^{\mathrm{b}}\end{array}$ \\
EOLSG & 12.479 & 1.332 & 0.712 & 0.641 & 0.373 \\
& $( \pm 5.165)^{\mathrm{c}}$ & $( \pm 0.231)^{\mathrm{c}}$ & $( \pm 0.057)^{\mathrm{a}}$ & $( \pm 0.063)^{\mathrm{ab}}$ & $( \pm 0.066)^{\mathrm{a}}$ \\
LGG & 0.433 & 0.081 & 0.694 & 0.632 & 0.386 \\
& $( \pm 0.070)^{\mathrm{a}}$ & $( \pm 0.023)^{\mathrm{a}}$ & $( \pm 0.043)^{\mathrm{a}}$ & $( \pm 0.049)^{\mathrm{b}}$ & $( \pm 0.048)^{\mathrm{a}}$ \\
EOLGG & 18.577 & 2.075 & 0.627 & 0.542 & $0.257 \mathrm{~b}$ \\
& $( \pm 5.527)^{\mathrm{d}}$ & $( \pm 0.607)^{\mathrm{b}}$ & $( \pm 0.049)^{\mathrm{b}}$ & $( \pm 0.047)$ & $( \pm 0.032)^{\mathrm{c}}$ \\
\hline
\end{tabular}

602

603 604

605

606

607

608

609

610

611

612

613

614

615

616

617

618

Table 2 -Mechanical parameters from compressive tests on pristine, lyophilized and laccaseoxidized, lyophilized fenugreek (LFG, EOLFG), sesbania (LSG, EOLSG) and guar gum (GG, EOLGG) aerogels.

Results are expressed as mean values and standard deviation (in brackets). Different superscripts within a group (i.e., within each parameter) refers to a statistically significant difference $(p<0.05)$. The three non-oxidized, lyophilized GM aerogels (i.e., LFG, LSG, LGG) did not exhibit appreciable differences in terms of $\mathrm{F}_{\max }$ and E-mod. However, after laccase oxidation it was possible to observe statistically significant differences between samples. In absolute terms, EOLFG aerogel was stiffer and harder than EOLSG and EOLGG, with EOLSG showing the lowest mean values of both $\mathrm{F}_{\max }$ and E-mod. Nevertheless, if we consider the relative increase of the above parameters, the largest occurred for EOLSG $\left(\mathrm{F}_{\max }\right.$ and E-mod increased $~ 50$ and 34 times, respectively). This observation seems to indicate that the oxidation, and resulting internal crosslinking, was somewhat more "efficient" in the case of SG than FG and GG, though SG ultimately yielded a relatively weaker aerogel.

Concerning the other mechanical parameters, cohesiveness represents the ability of the sample to stand a second deformation in relation with the sample behavior during the first deformation cycle. Springiness indicates the capability of the sample to spring back after the first compression. Resilience is a measure of the ability of the sample to recover its original shape. After oxidation, cohesiveness and springiness decreased significantly only for the GG samples. Resilience decreased significantly upon oxidation for all the three samples, consistent with the inverse relationship between this parameter on one hand, and the compressive modulus and maximum force on the other (Ghafar et al., 2015). 
Although the results of the mechanical tests unambiguously demonstrate positive effect of 627 enzymatic oxidation on gel structuring, it is clear that the crosslinking efficiency depends on the specific polysaccharide and the formation of hemiacetal bonds at inter- and intra- molecular level.

\section{Conclusions}

631 There is an increasing interest in the development of new biomaterials from renewable resources, 632 possibly by means of sustainable biochemical reactions. Indeed, plant polysaccharides represent a 633 valuable and sustainable alternative to traditional synthetic polymers produced from monomers of 634 fossil, non-renewable origin and are increasingly applied in a growing number of industrial fields, 635 either in their natural or chemically/biochemically modified forms. Enzyme modifications of 636 polysaccharides is still an open field of investigation and product development. However, while 637 glycohydrolases (e.g., amylases, cellulases, mannanases, etc.) are currently widely used enzymes for 638 depolymerization, the family of redox enzymes (e-g., dehydrogenases and oxidases) have so far been 639 relatively less studied and applied to generate "functional" polymers and new biomaterials (see also 640 Karaki, Aljawish, Hueau, Muniglia \& Jasniewski, 2016). Galactomannans are employed to produce a 641 considerable range of derivatives with numerous applications in food, feed and industrial fields. 642 These are versatile and quite reactive polysaccharides, that, from an agronomic point of view, offer 643 the advantage of being reserve polysaccharides of leguminous plants grown in sub-tropical and semi644 arid areas of the world, requiring little or no fertilizing and limited artificial watering, compared to 645 starch-containing cereals. In the present work, we have applied to three different GM the laccase646 mediator oxidation system previously described (Lavazza et al, 2011), followed by lyophilization, 647 and have shown that oxidation is a key factor in the generation of aerogels with enhanced overall 648 features and performance. However, differences among the oxidized GM suggest that the chemical 649 composition of the polysaccharides (i.e., the galactose : mannose ratio) appears to play an important 650 role. Fenugreek exhibited the best performance in terms of mechanical properties over guar and 651 sesbania gums, which is likely due to its highest amount of galactose along the mannose backbone 652 (Gal : Man =1:1).

653 We suggest that the findings reported might be useful in the designing of novel nanostructured 654 biomaterials with tailored functional properties as biocompatible, flexible delivery systems of various 655 actives (for a comprehensive review, see Ulker \& Erkey, 2014), as well as for food packaging or 656 insulating devices.

657 More studies are needed to establish their real potential and applicability. Few lines of investigation 658 are ongoing to clarify various aspects of these systems, such as: freeze-drying protocols to influence 659 pore and size formation, range of actives that can be uploaded and released, kinetics of release, role 
660 of temperature and humidity on aerogels performance, long term activity preservation, stability in 661 order to ensure long-term antimicrobial protection.

662 


\section{Acknowledgements}

664 We wish to thank Dr. Sergio Riva for constant support, suggestions and criticism throughout this 665 project, Dr. Lucia Galimberti for performing the MIP and Prof Alessandra Polissi for suggesting the 666 testing and the gift of a polymyxin B sample.

667 The supply of GM gums from guar, sesbania and fenugreek by Lamberti SpA is gratefully 668 acknowleged.

669 This project was supported by the program "Suschem Lombardia: prodotti e processi chimici 670 sostenibili per l'industria lombarda". Accordo Quadro Regione Lombardia-CNR, 16/07/2012 671 (protocol no. 18096/RCC), by Cariplo Foundation (grant 2014-0478). 


\section{References}

Alexopoulou, A., Vasilieva, L., Agiasotelli, D., Siranidi, K., Pouriki, S., Tsiriga, A., Toutousa, M. \& Dourakis, S. P. (2016). Extensively drug-resistant bacteria are an independent predictive factor of mortality in 130 patients with spontaneous bacterial peritonitis or spontaneous bacteremia. World Journal of Gastroenterology, 22 (15), 4049.

Al-Homoud, M. (2005). Performance characteristics and practical applications of common building thermal insulation materials. Build. Environ., 40, 353-366.

Altschul, S.F., Gish, W., Miller, W., Myers, E. W. \& Lipman D.J. (1990). Basic local alignment search tool. J. Mol. Biol., 215, 403-410.

Ávila, M., Gómez-Torres, N., Hernández, M., \& Garde, S. (2014). Inhibitory activity of reuterin, nisin, lysozyme and nitrite against vegetative cells and spores of dairy-related Clostridium species. Intl. J. Food Microb., 172, 70-75.

Blomfeldt, T. O. J., Olsson, R. T. Menon, M., Plackett, D., Johansson, E. \& Hedenqvist, M. S. (2010). Macromol. Mater. Eng., 295, 796-864.

Borrelli, G. M. \& Trono, D. (2015). Recombinant lipases and phospholipases and their use as biocatalysts for industrial applications. Int. J. Mol. Sci., 16 (9), 20774-20840.

Boziaris, I. S., \& Adams, M. R. (1999). Effect of chelators and nisin produced in situ on inhibition and inactivation of Gram negatives. International Journal of Food Microbiology, 53 (2), 105-113. Bradford, M. M. (1976). A rapid and sensitive method for the quantitation of microgram quantities of proteins utilizing the principle of protein-dye binding. Analitycal Biochemistry, 72, 248-254.

Brasca, M., Morandi, S., Silvetti, T., Rosi, V., Cattaneo, S., \& Pellegrino, L. (2013). Different analytical approaches in assessing antibacterial activity and the purity of commercial lysozyme preparations for dairy application. Molecules, 18, 6008-6020.

Cheng, Y., Prud'homme, R. K., Chick, J., \& Rau, D. C. (2002). Measurement of Forces between Galactomannan Polymer Chains: Effect of Hydrogen Bonding. Macromol., 35, 10155-10161.

Commission Directive 2010/69/EU of 22 October 2010. (2010). Official Journal of the European Union, 1-31.

Commission Regulation (EU) No 1129/2011 of 12 November 2011. (2011). Official Journal of the European Union, 1-177.

Crescenzi, V., Dentini, M., Risica, D., Spadoni, S., Skjak-Braek, G., Capitani, D., Mannina, L., \& Viel, S. (2004). C(6)-Oxidation Followed by C(5)- Epimerization of Guar Gum Studied by High Field NMR. Biomacromol., 5, 537-546. 
706 Daas, P. J. H., Schols, H. A., \& de Jongh, H. H. J. (2000). On the galactosyl distribution of 707 commercial galactomannans. Carboydr. Res., 329, 609-619.

708 Daas, P. J. H., Grolle, K., van Vliet, T., Schols, H. A., \& de Jongh, H. H. J. (2002). Toward the 709 Recognition of Structure-Function Relationships in Galactomannans. J. Agric. Food Chem., 50, $710 \quad 4282-4289$.

711 Daniel, J. R., Whistler, R. L., Voragen, A. G. J., \& Pilnik, W. (1994). Starch and other 712 Polysaccharides. In B. Elvers, S. Hawkins \& W. Russey, Ulmann's Encyclopedia of Industrial 713 Chemistry, Vol. A25 ( pp. 1-62), Weinheim, Germany: VCH.

714 de Arauz, L. J., Jozala, A. F., Mazzola, P. G., \& Penna, T. C. V. (2009). Nisin biotechnological 715 production and application: a review. Trends in Food Science \& Technology, 20 (3), 146-154.

716 Deszczynski, M., Kasapis, S., \& Mitchell, J. R. (2003). Rheological investigation of the structural 717 properties and aging effects in the agarose/co-solute mixture. Carbohydrate Polymers, 53, 85-93.

718 European Food Safety Authority (EFSA) (2006). Opinion of the Scientific Panel on food additives, 719 flavourings, processing aids and materials in contact with food (AFC) related to the safety in use of 720 nisin as a food additive in an additional category of liquid eggs. EFSA Journal, 4 (12), 1-8.

721 Falagas, M. E., Kasiakou, S. K., \& Saravolatz, L. D. (2005). Colistin: the revival of polymyxins for 722 the management of multidrug-resistant gram-negative bacterial infections. Clinical Infectious 723 Diseases, 40 (9), 1333-1341.

724 Fang, T. J., \& Tsai, H. C. (2003). Growth patterns of Escherichia coli O157: H7 in ground beef 725 treated with nisin, chelators, organic acids and their combinations immobilized in calcium alginate 726 gels. Food Microbiology, 20 (2), 243-253.

727 Fu, J., Su, J., Wang, P., Yu, Y., Wang, Q. \& Cavaco-Paulo, A. (2015). Enzymatic processing of 728 protein-based fibers. Appl. Microbiol. Biotechnol.,99 (24), 10387-10397.

729 Ghafar, A., Parikka, K., Sontag-Strohm, T., Osterberg, M., Tenkanen, M., \& Mikkonen, K. S. 730 (2015). Strengthening effect of nanofibrillated cellulose is dependent on enzymatically oxidized 731 polysaccharide gel matrices. European Polymer J., 71, 171-184.

732 Gupta, R., Beg, Q. K. \& Lorenz, P. (2002). Bacterial alkaline proteases: molecular approaches and 733 industrial applications. Appl. Microbiol. Biotechnol., 59 (1), 15-32.

734 Jaeger K. E. \& Eggert T. (2002). Lipases for biotechnology. Curr. Opin. Biotechnol., 13 (4), 390735397.

736 Jiang, F. \& Hsieh, Y. L. (2014). Super water absorbing and shape memory nanocellulose aerogels 737 from TEMPO-oxidized cellulose nanofibrils via cyclic freezing - thawing. J. Mater. Chem. A, 2, $738 \quad 350-359$. 
Joshi, M. K., Pant, H. R., Tiwari, A. P., Kim, H. J., Park, C. H. \& Kim, C. S. (2015). Multi-layered 740 macroporous three-dimensional nanofibrous scaffold via a novel gas foaming technique. Chem. 741 Eng. J., 275, 79-88.

742 Karaki, N., Aljawish, A., Humeau, C., Muniglia, L. \& Jasniewski, J. (2016). Enzymatic 743 modification of polysaccharides: Mechanisms, properties, and potential applications: A review. 744 Enzyme and Microbial Technol. 90, 1-18.

745 Karn, S. K. \& Kumar, A. (2015). Hydrolytic enzyme protease in sludge: recovery and its 746 application. Biotechnology and Bioprocess Engineering, 20 (4), 652-661.

747 Kim, S. H. \& Chu, C. C. (2000). Pore structure analysis of swollen dextran-methacrylate hydrogels 748 by SEM and mercury intrusion porosimetry. J. Biomed. Mater. Res., 53, 258-266.

749 Kim, Y. J., Oh, D. H., Song, B. R., Heo, E. J., Lim, J. S., Moon, J. S., Park, H. J., Wee, S. H. \& Sung, 750 K. (2015). Molecular characterization, antibiotic resistance, and virulence factors of methicillin751 resistant Staphylococcus aureus strains isolated from imported and domestic meat in Korea.

752 Foodborne Pathogens and Disease, 12 (5), 390-398.

753 Lavazza, M., Formantici, C., Langella, V., Monti, D., Pfeiffer, U., \& Galante, Y. M. (2011). 754 Oxidation of galactomannan by laccase plus TEMPO yields an elastic gel. J. Biotechnol. 156, 108755116.

756 Li, J.; Rayner, C. R. \& Nation, R. L. (2005). Colistin-associated acute renal failure: revisited. South. Med. J., 98, 1229-1230.

758 Lin, R. Li, A., Lu, L. \& Cao, Y. (2015). Preparation of bulk sodium carboxymethyl cellulose 759 aerogels with tunable morphology. Carbohydrate Polymers, 118, 126-132

760 Lin, Y., Chen, Z. \& Liu, X.Y. (2016). Using inorganic nanomaterials to endow biocatalytic systems 761 with unique features. Trends in Biotechnol., 34 (4), 303-315.

762 Liyanage, S., Abidia, N., Auldb, D., \& Moussa, H. (2015). Chemical and physical characterization 763 of galactomannan extracted from guar cultivars (Cyamopsis tetragonolobus L.). Industr. Crops \& 764 Products, 74, 388-396.

765 Mathur, M. K. (2011). Industrial Galactomannan polysaccharides. Boca Raton, Florida: CRC 766 Press.

767 Majda, D., Zimowska, M., Tarach, K., Góra-Marek, K., Napruszewska, B. D. \& Michalik-Zym, A. 768 (2016). Water thermoporosimetry as a tool of characterization of the textural parameters of 769 mesoporous materials. J. Therm. Anal. Calorim., in press. DOI: 10.1007/s10973-016-5400-3.

770 McCabe K. M., Zhang Y. H., Khan G., Mason E. O. \& McCabe E. R. B. (1995). Amplification of 771 bacterial DNA using highly conserved sequences: automated analysis and potential for molecular 772 triage of sepsis. Pediatrics, 95, 165-169. 
McCleary, B. V., Clark, A. H., Dea, I. C. M. \&, Rees, D. A. (1985). The fine structures of carob and guar galactomannans. Carbohydr. Res., 139, 237-260.

Meghwal, M., Goswami, T. K. (2012). A review on the functional properties, nutritional content, medicinal utilization and potential application of fenugreek. J Food Process. Technol., 3, 181.

Merlini, L., Boccia, A. C., Mendichi, R., \& Galante, Y. M. (2015). Enzymatic and chemical oxidation of polygalactomannas from the seeds of a few species of leguminous plants and characterization of the oxidized products. J. Biotechnol., 198, 31-43.

Murthy, P. S., Moorthy, R., Prabhu, K. M., \& Puri D. (2010). Anti-diabetic and cholesterol lowering preparation from fenugreek seeds. Patent US7815946 B1.

Niku-Paavola, M. L., Karhunen, E., Salola, P., \& Raunio, V. (1988). Ligninolytic enzymes of the white-rot fungus Phlebiaradiata. Biochem. J., 254, 877-884.

Payne, D. J., Gwynn, M. N., Holmes, D. J. \& Pompliano, D. L. (2007). Drugs for bad bugs: confronting the challenges of antibacterial discovery. Nat. Rev. Drug Discovery, 6, 29-40.

Prajapati, V. D., Jani, G. K., Moradiya, N. G., Randeria, N. P., Nagar, B. J., Naikwadi, N. N., \& Variya, B. C. (2013). Galactomannan: A versatile biodegradable seed polysaccharide. Intl. J. Biol. Macromol., 60, 83-92.

Reetz M. T (2002). Lipases as practical biocatalysts. Curr. Opin. Biotechnol., 6 (2), 145-150.

Rossi, B., Campia, P., Merlini, L., Brasca, M., Pastori, N., Farris, S., Melone, L., Punta., C. \& Galante, Y. M. (2016). An aerogel obtained from a chemo-enzymatically oxidized fenugreek galactomannans as a versatile delivery system. Carbohydr. Polym., 144, 353-361.

Sahl, H. G., Jack, R. W., \& Bierbaum, G. (1995). Biosynthesis and biological activities of lantibiotics with unique post-translational modifications. European J. Biochem., 230, 827-853.

Sajben E., Manczingera L., Nagyb A., Kredicsa L. \& Vágvölgyia C. (2011). Characterization of Pseudomonas isolated from decaying sporocarps of oyster mushroom. Microbiol. Res., 166, 255267.

Santambrogio, C., Sasso, F., Natalello, A., Brocca, S., Grandori, R., Doglia, S. M. \& Lotti, M. (2013). Effects of methanol on a methanol-tolerant bacterial lipase. Appl. Microbiol. Biotechnol, 97 (19), 8609-8618.

Santos, S. M., Carbajo, J. M., Quintana, E., Ibarra, D., Gomez, N., Ladero, M., Eugenio, M. E. \& Villar, J. C. (2015). Characterization of purified bacterial cellulose focused on its use on paper restoration. Carbohydrate Polymers, 116, 173-181.

Silvetti, T., Brasca, M., Lodi, R., Vanoni, L., Chiolerio, F., de Groot, M. \& Bravi, A. (2010). Effects of lysozyme on the microbiological stability and organoleptic properties of unpasteurized beer. J. Inst. Brewing, 116, 33-40. 
Sittikijyothin, W., Torres, D., \& Gonçalves, M. P. (2005), Modelling the rheological behaviour of galactomannan aqueous solutions. Carbohydrate Polymers, 59, 339-350.

Souza, P. M., Assis Bittencourt, M. L., Caprara, C. C., Freitas, M., Almeida, R. P. C., Silveira, D., Fonseca, Y. M., Filho, E. X. F., Pessoa Junior, A \& Magalhães, P.O. (2015). A biotechnology perspective of fungal proteases. Brazilian J. Microb., 46 (2), 337-346.

Steinbach, C. L., Töpper, C., Adam, T., \& Kees, M. G. (2015). Spectrum adequacy of antibiotic regimens for secondary peritonitis: a retrospective analysis in intermediate and intensive care unit patients. Annals of Clinical Microb. \& Antimicrobials, 14 (1), 1.

Svagan, A. J., Samir, M. A. S. A. \& Berglund L. A. (2008). Biomimetic foams of high mechanical performance based on nanostructured cell walls reinforced by native cellulose nanofibrils. Adv. Mater., 20, 1263-1269.

Takahashi, H., Kuramoto, S., Miya, S., Koiso, H., Kuda, T., \& Kimura, B. (2011). Use of commercially available antimicrobial compounds for prevention of Listeria monocytogenes growth in ready-to-eat minced tuna and salmon roe during shelf life. J. Food Protection, 74(6), 994-998. Talbot G. H., Bradley, J., Edwards, J. E., Gilbert, D., Scheld, M. \& BartletT, J. G. (2006). Bad bugs need drugs: an update on the development pipeline from the Antimicrobial Availability Task Force of the Infectious Diseases Society of America. Clin. Infect. Dis., 42, 657-668.

Tong, Z., Zhang, Y., Ling, J., Ma, J., Huang, L., \& Zhang, L. (2014). An in vitro study on the effects of nisin on the antibacterial activities of 18 antibiotics against Enterococcus faecalis. PloS one, $9(2)$.

Ulker, Z. \& Erkey, C. (2014) An emerging platform for drug delivery: Aerogel based systems. J. Controlled Release, 177, 51-63.

Vaara, M. (1992). Agents that increase the permeability of the outer membrane. Microbiological reviews, 56 (3), 395-411.

Vaghari, H., Jafarizadeh-Malmiri, H., Mohammadlou, M., Berenjian, A., Anarjan, N., Jafari, N. \& Nasiri, S. (2016). Application of magnetic nanoparticles in smart enzyme immobilization.

Biotechnol. Lett., 38 (2), 223-233.

Velkov, T., Thompson, P. E., Nation, R. L., \& Li, J. (2009). Structure--activity relationships of polymyxin antibiotics. Journal of Medicinal Chemistry, 53 (5), 1898-1916.

Verma, M.L., Puri, M. \& Barrow, C.J. (2016). Recent trends in nanomaterials immobilised enzymes for biofuel production. Crit. Rev. Biotechnol., 36 (1), 108-119.

Washburn, E. W. (1921). Note on a method of determining the distribution of pore sizes in a porous material. Proc. Natl. Acad. Sci., 7, 115-116. 
840 Webb, P. A. \& Orr, C. (1997). Analytical methods in fine particle technology. Norcross: 841 Micromeritics Publishers.

842 Wei, Y., Lin, Y., Xie, R., Xu, Y., Yao, J., \& Zhang, J. (2015). The flow behavior, thixotropy and 843 dynamical viscoelasticity of fenugreek gum. J. Food Eng., 166, 21-28.

844 Wicklein, B., Kocjan, A., Salazar-Alvarez, G., Carosio, F., Camino, G., Antonietti, M. \& 845 Bergström, L. (2015). Thermally insulating and fire-retardant lightweight anisotropic foams based 846 on nanocellulose and graphene oxide. Nat. Nanotechnol., 10, 277-283.

847 Zavascki, A. P., Goldani, L. Z., Li, J., \& Nation, R. L. (2007). Polymyxin B for the treatment of 848 multidrug-resistant pathogens: a critical review. J. Antimicrobial Chemotherapy, 60 (6), 1206-1215. 849 
Table 1 - MIP parameters of the three GM aerogels

\begin{tabular}{cccccc}
\hline Sample & $\begin{array}{c}\text { Bulk density } \\
\left(\mathbf{k g ~ x ~ m}^{-\mathbf{3}}\right)\end{array}$ & $\begin{array}{c}\text { Porosity } \\
(\boldsymbol{\%})\end{array}$ & $\begin{array}{c}\text { Pore surface area } \\
\left(\mathbf{m}^{\mathbf{2}} \mathbf{\times} \mathbf{~ g}^{-\mathbf{1}}\right)\end{array}$ & $\begin{array}{c}\text { Average pore diameter } \\
(\boldsymbol{\mu m})\end{array}$ & $\begin{array}{c}\text { Modal pore diameter } \\
(\boldsymbol{\mu m})\end{array}$ \\
\hline EOLFG & 35.9 & 99.91 & 11.32 & 9.83 & 42.44 \\
EOLSG & 32.8 & 96.19 & 16.89 & 6.94 & 3.59 \\
EOLGG & 31.3 & 93.28 & 15.54 & 7.68 & 102.71 \\
\hline
\end{tabular}


Table 2 - Mechanical parameters from compressive tests on pristine, lyophilized and laccase-oxidized, lyophilized fenugreek (LFG, EOLFG), sesbania (LSG, EOLSG) and guar gum (GG, EOLGG) aerogels.

\begin{tabular}{lccccc}
\hline Sample & $\begin{array}{c}\text { E-mod } \\
(\mathbf{k P a})\end{array}$ & $\begin{array}{c}\mathbf{F}_{\max } \\
(\mathbf{N})\end{array}$ & Cohesiveness & Springiness & Resilience \\
& 0.502 & 0.081 & 0.713 & 0.651 & 0.393 \\
LFG & $( \pm 0.085)^{\mathrm{a}}$ & $( \pm 0.014)^{\mathrm{a}}$ & $( \pm 0.040)^{\mathrm{a}}$ & $( \pm 0.042)^{\mathrm{ab}}$ & $( \pm 0.033)^{\mathrm{ab}}$ \\
& 22.775 & 2.376 & 0.685 & 0.611 & 0.316 \\
EOLFG & $( \pm 5.792)^{\mathrm{b}}$ & $( \pm 0.548)^{\mathrm{b}}$ & $( \pm 0.034)^{\mathrm{a}}$ & $( \pm 0.038)^{\mathrm{a}}$ & $( \pm 0.037)^{\mathrm{c}}$ \\
& 0.249 & 0.039 & 0.728 & 0.665 & 0.434 \\
LSG & $( \pm 0.083)^{\mathrm{a}}$ & $( \pm 0.012)^{\mathrm{a}}$ & $( \pm 0.033)^{\mathrm{a}}$ & $( \pm 0.033)^{\mathrm{b}}$ & $( \pm 0.034)^{\mathrm{b}}$ \\
& 12.479 & 1.332 & 0.712 & 0.641 & 0.373 \\
EOLSG & $( \pm 5.165)^{\mathrm{c}}$ & $( \pm 0.231)^{\mathrm{c}}$ & $( \pm 0.057)^{\mathrm{a}}$ & $( \pm 0.063)^{\mathrm{ab}}$ & $( \pm 0.066)^{\mathrm{a}}$ \\
& 0.433 & 0.081 & 0.694 & 0.632 & 0.386 \\
LGG & $( \pm 0.070)^{\mathrm{a}}$ & $( \pm 0.023)^{\mathrm{a}}$ & $( \pm 0.043)^{\mathrm{a}}$ & $( \pm 0.049)^{\mathrm{ab}}$ & $( \pm 0.048)^{\mathrm{a}}$ \\
& 18.577 & 2.075 & 0.627 & 0.542 & 0.257 \\
EOLGG & $( \pm 5.527)^{\mathrm{d}}$ & $( \pm 0.607)^{\mathrm{b}}$ & $( \pm 0.049)^{\mathrm{b}}$ & $( \pm 0.047)^{\mathrm{c}}$ & $( \pm 0.032)^{\mathrm{d}}$ \\
\hline
\end{tabular}


Fig. 1-a,b
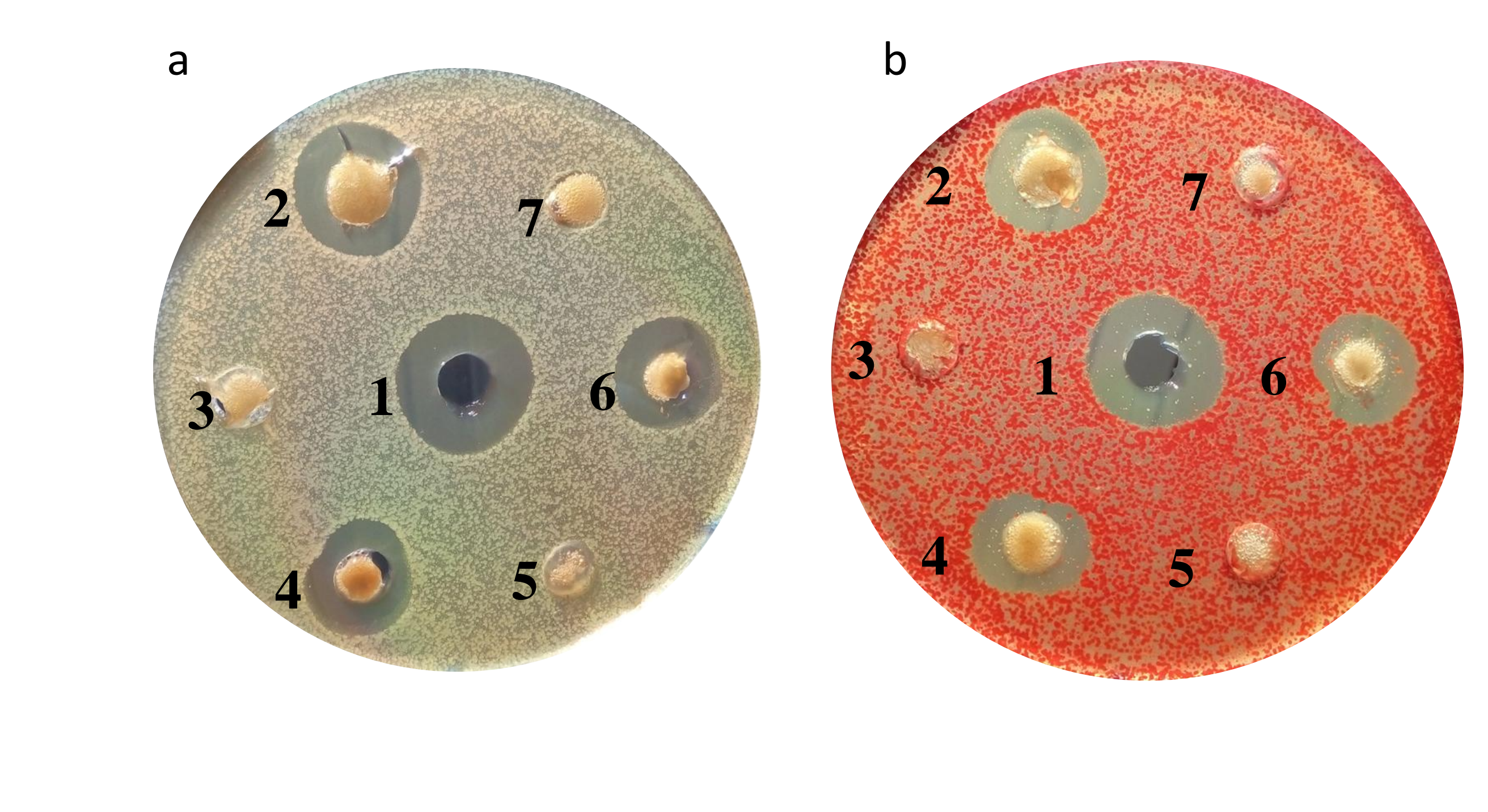
Fig. 1-c,d,e

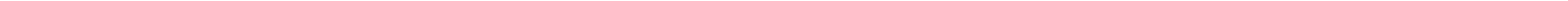


Fig. 2-a,b
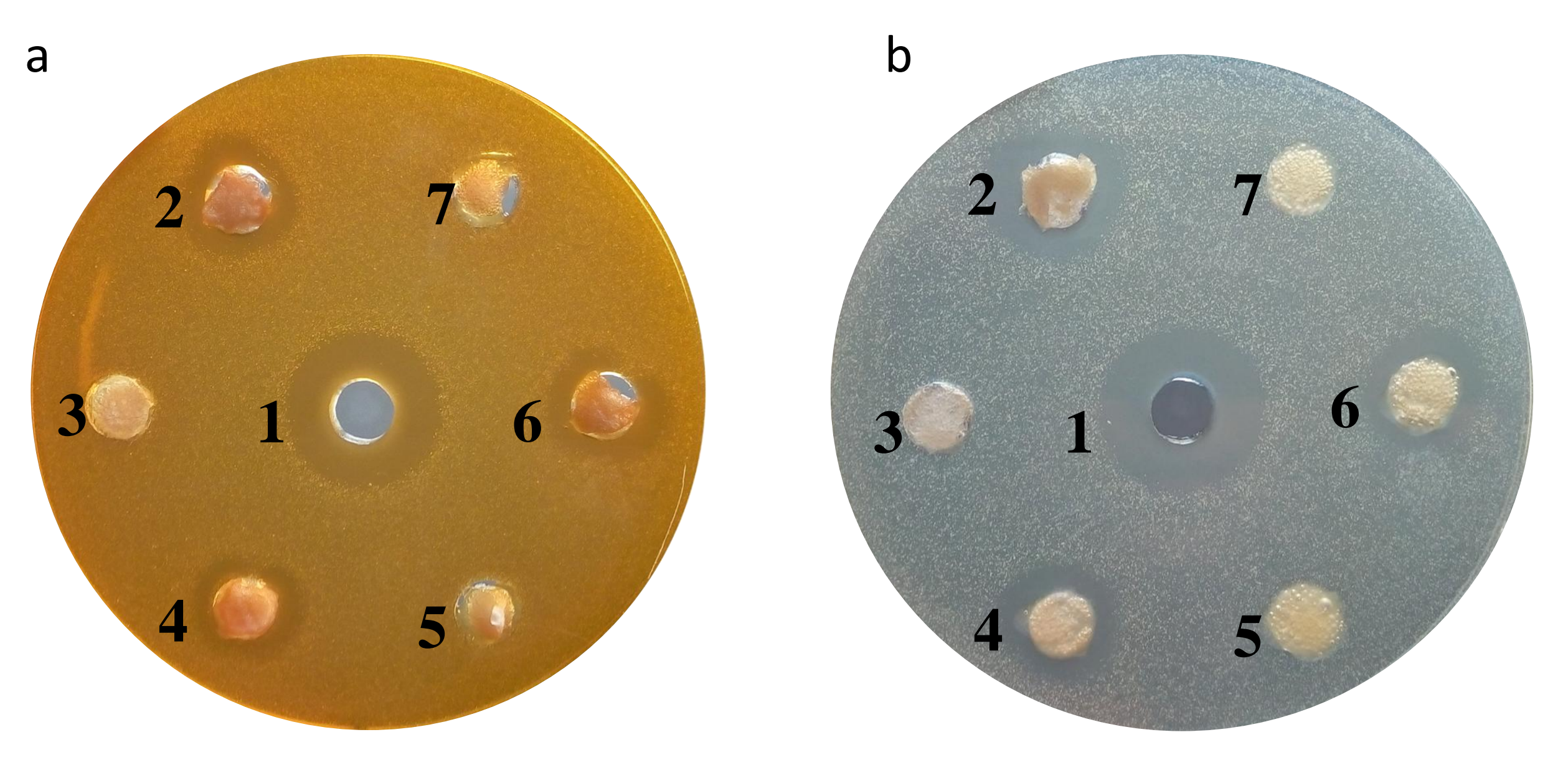
Figure 4

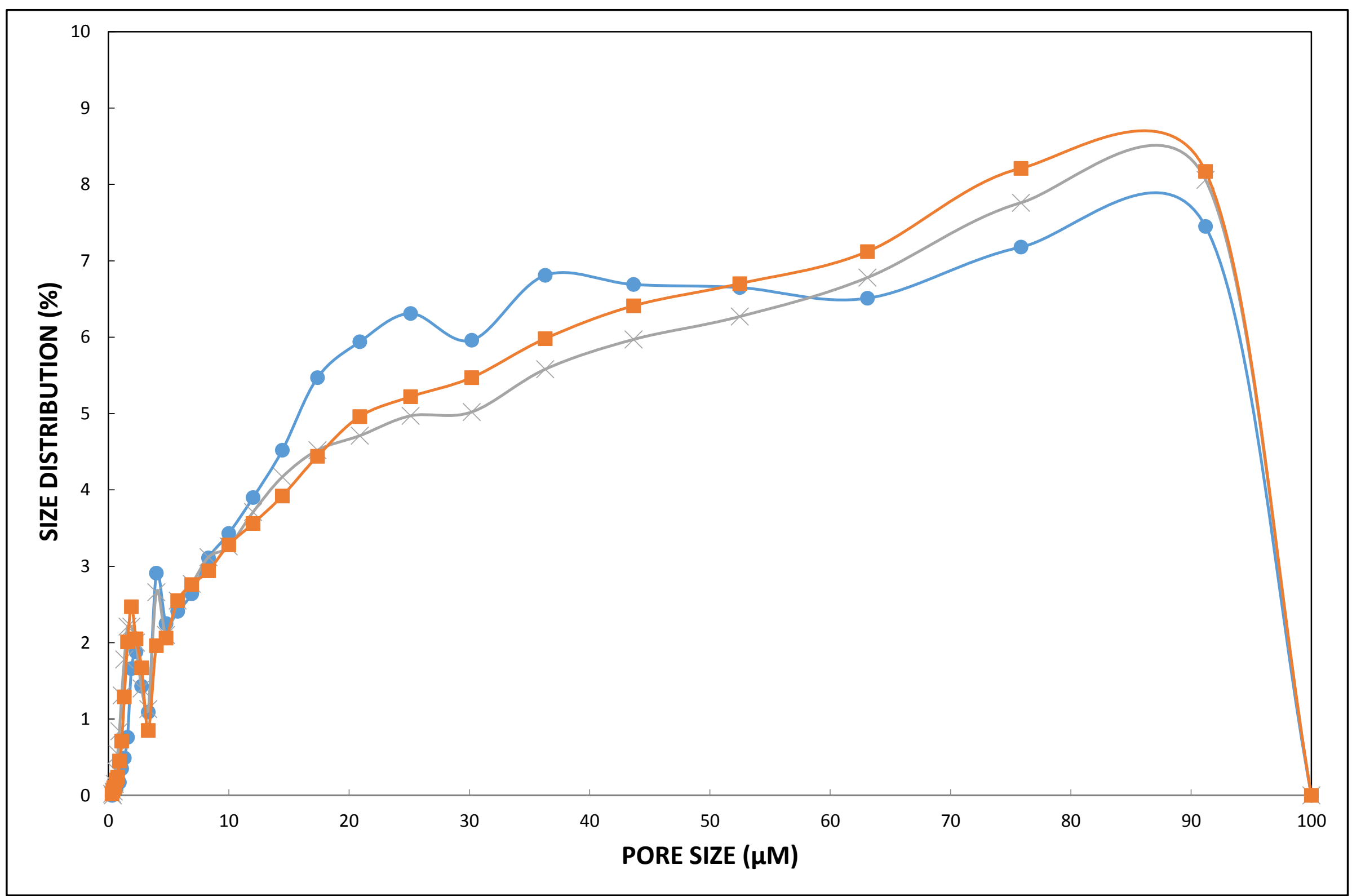




\section{Figure legends}

Fig. 1- Inhibition by polymyxin B released from aerogels of Gram-negative bacterial cell growth. Central well (1), $30 \mu \mathrm{g}$ (equivalent to 22 nanomoles) of free polymyxin B. Lateral wells: plugs of loaded EOLFG (2), control EOLFG (3); loaded EOLSG (4), control EOLSG (5); loaded EOLGG (6), control EOLGG (7). Fig. 1a: P. aeruginosa. Fig. 1b: S. marcescens. Fig. 1c: S. Typhimurium. Fig. 1d: E. coli. Fig. 1e: E. cloacae.

Fig. 2 - Inhibition by nisin released from aerogels of Gram-positive bacterial cell growth. Central well (1) $125 \mu \mathrm{g}$ of free nisin (equivalent to 37 nanomoles). Lateral wells: plugs of loaded EOLFG (2), control EOLFG (3); loaded EOLSG (4), control EOLSG (5); loaded EOLGG (6), control EOLGG(7). Fig. 2a: E. faecalis. Fig. 2b: C. tyrobutirycum.

Fig. 3 - Time course of protease release in water solution from "loaded" hydrogel plugs of EOLFG, EOLSG and EOLGG. Each time point was performed in triplicate on separately prepared plugs and is expressed as the average percentage of the "theoretical" total protease activity loaded.

Fig. 4- Pore size distribution in diameter (abscissa) $v s$ their \% distribution (ordinate) of the three GM aerogels (blue curve (•), EOLFG; green curve (x), EOLSG; red curve (๘), EOLGG. 


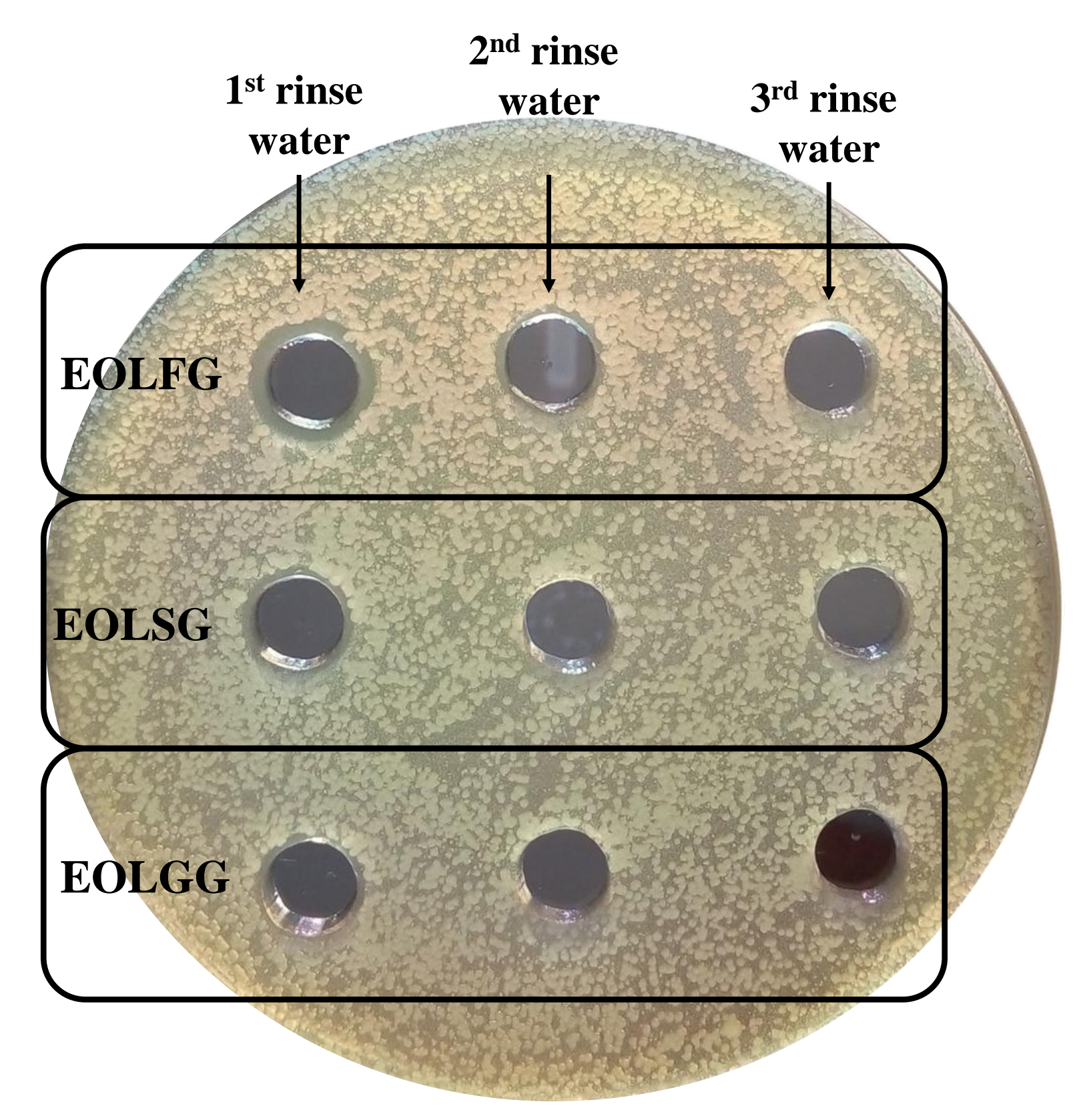

Fig. 1.S 


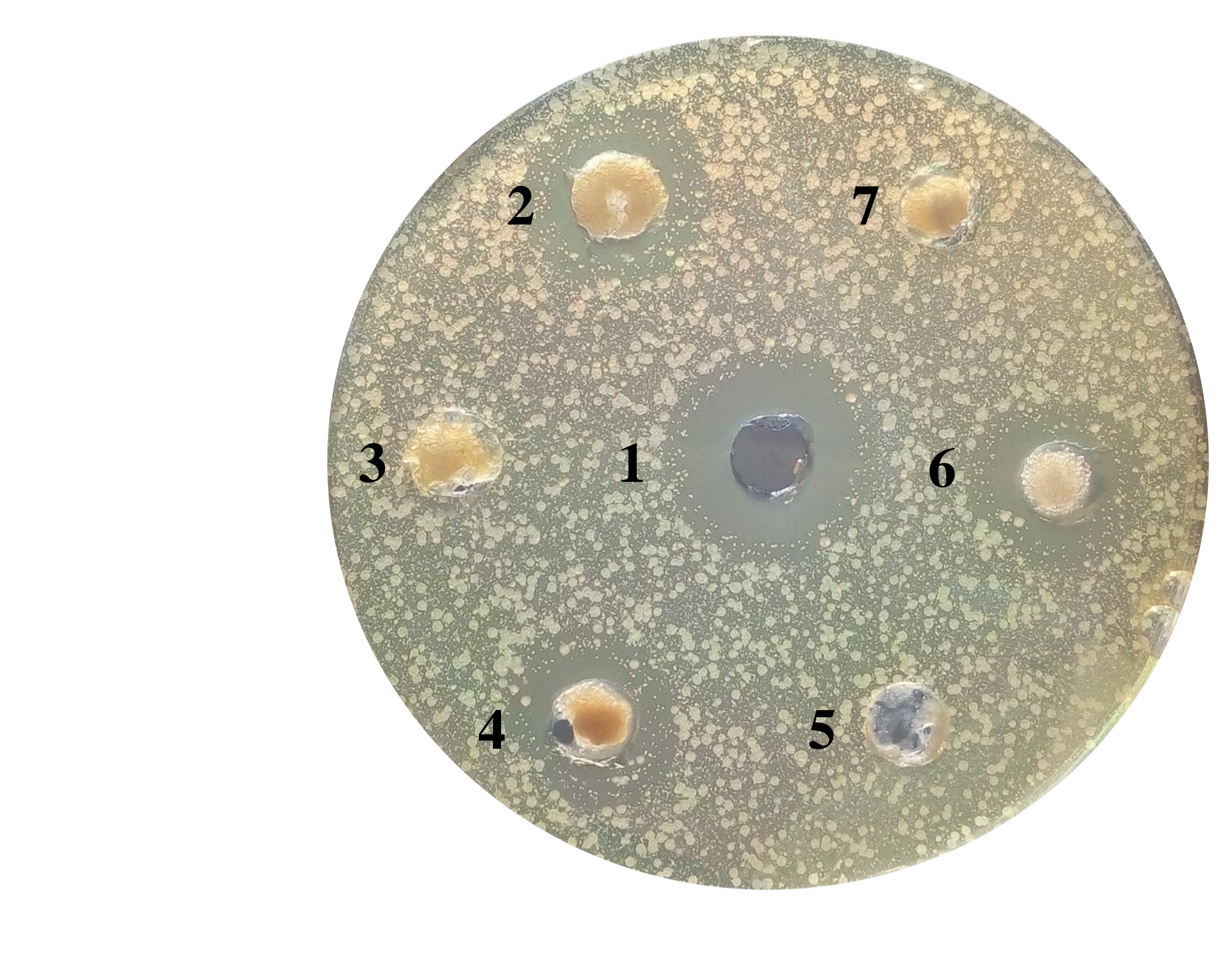

\section{Fig. 3.S}
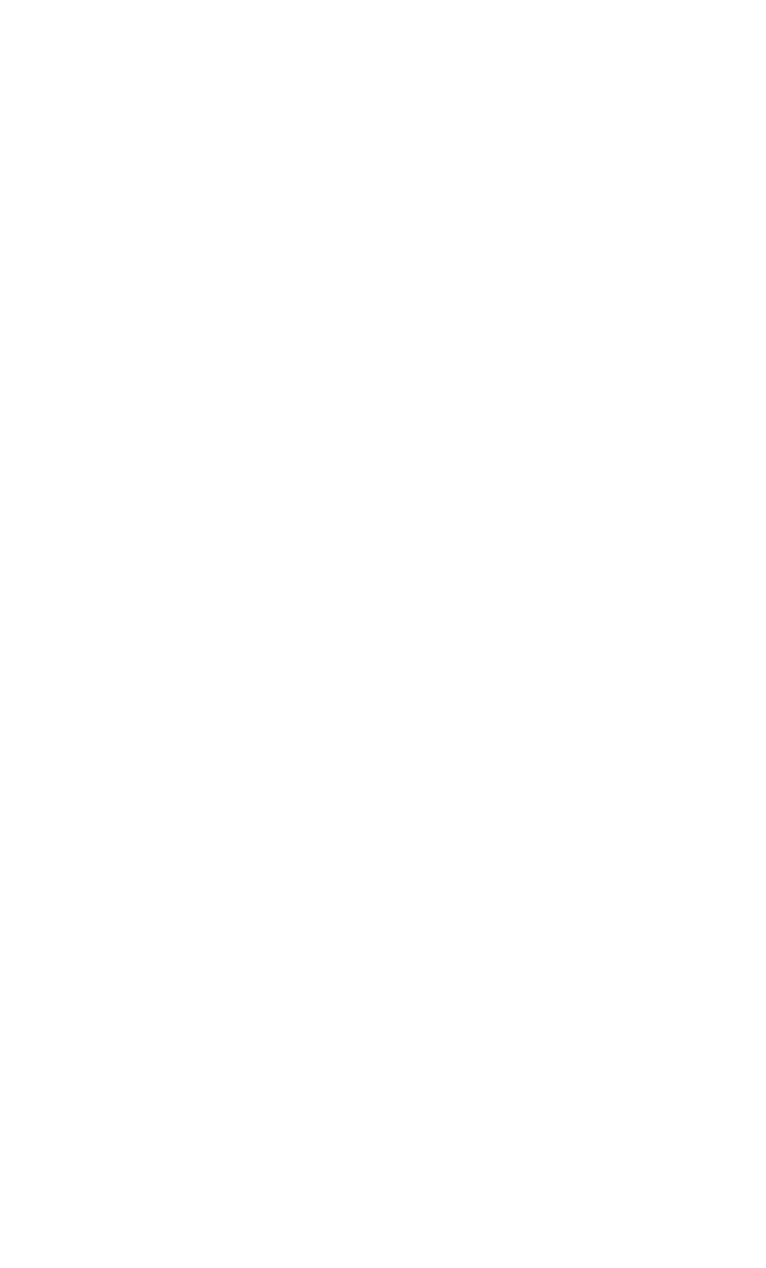
Fig. 5.S

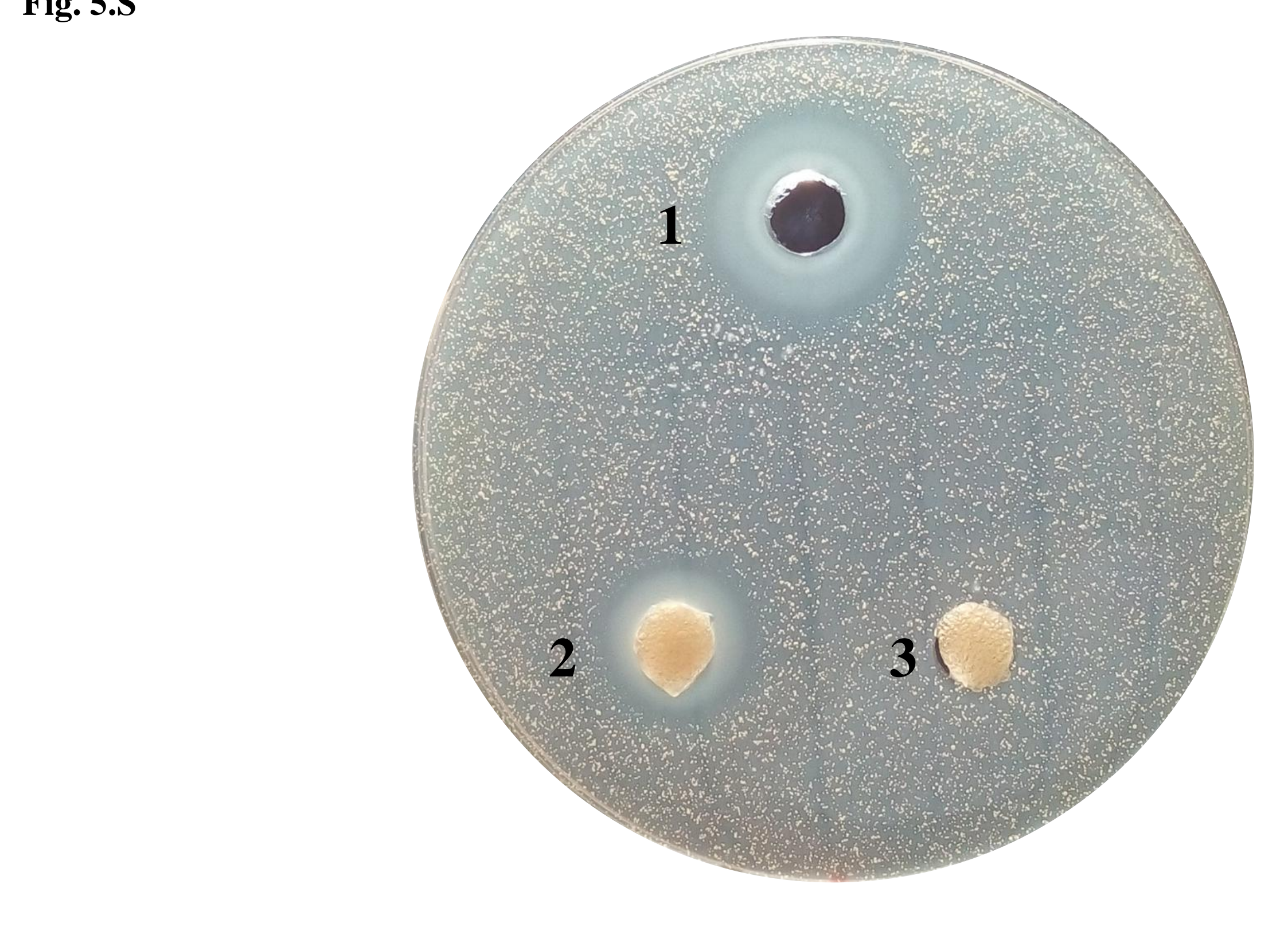
Fig. 5.S

s


Fig. 6.S

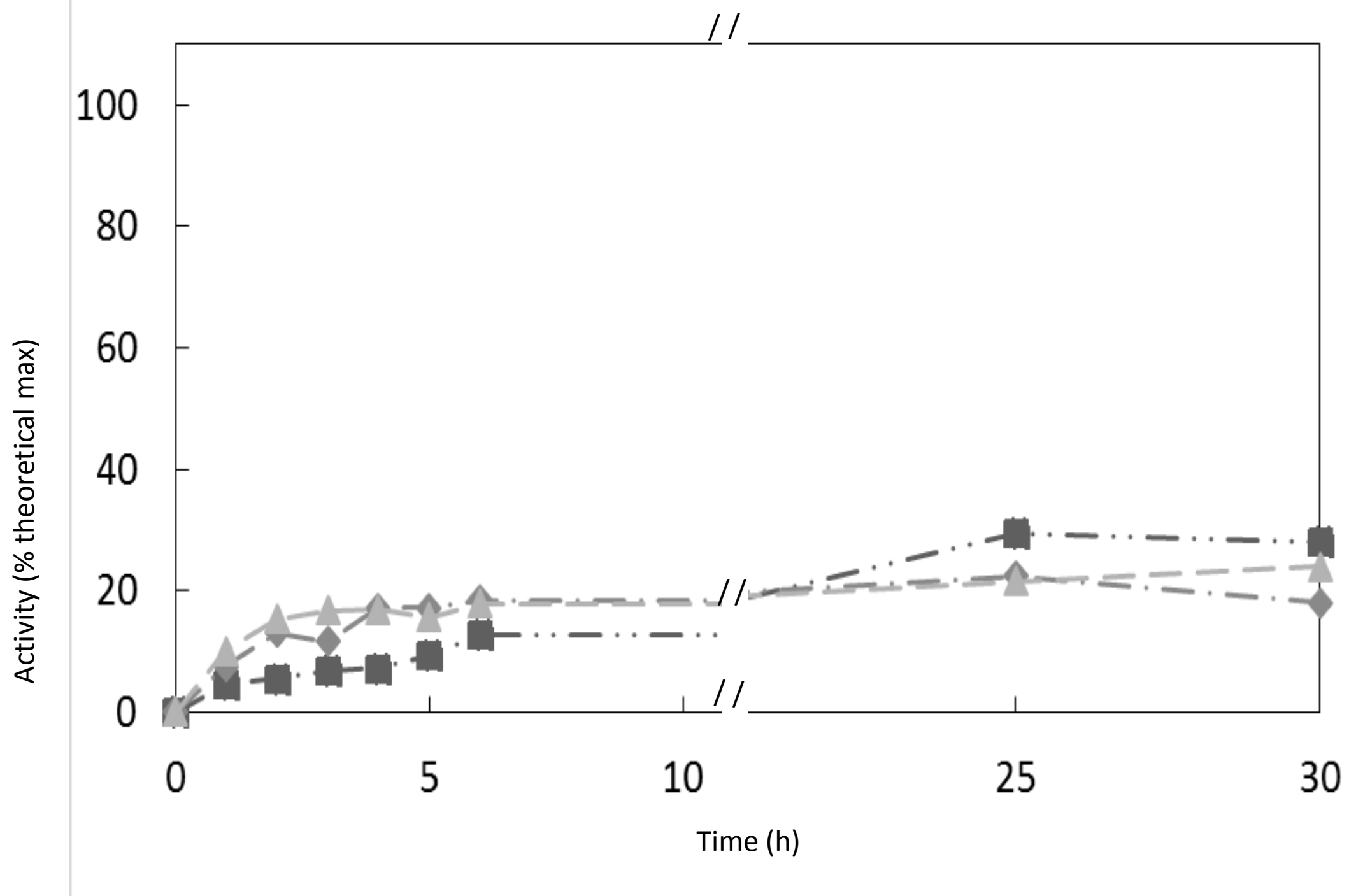




\section{Figure 7.S}
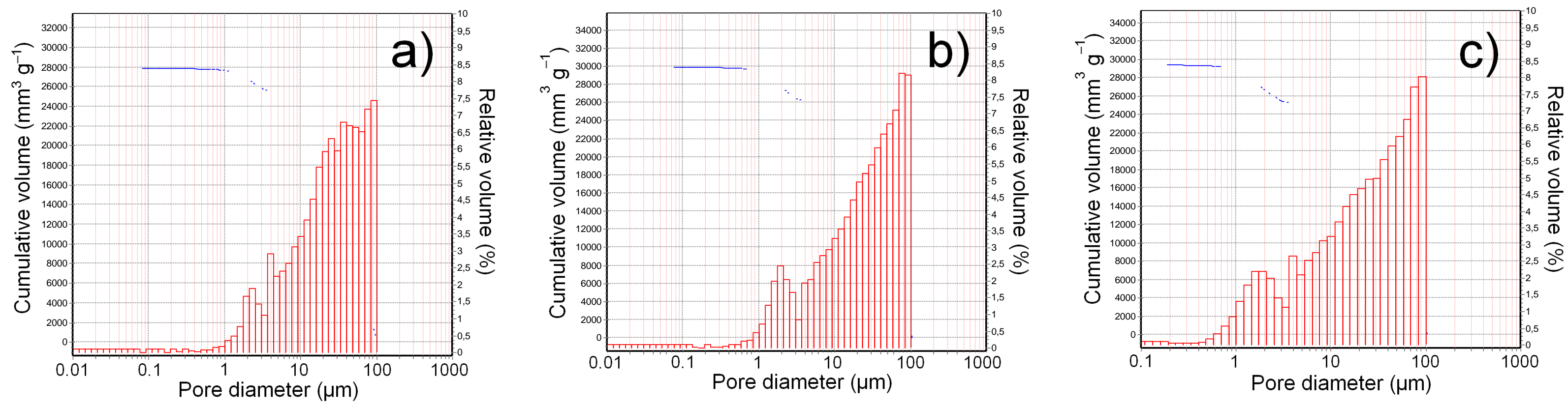


\section{SUPPLEMENTARY MATERIALS}

\section{Legends to Figures}

Fig. 1.S - Rinse water of EOLFG, EOLSG, EOLGG plugs loaded with polymyxin B (from Fig. 1.a) and checked for cell growth inhibition of $P$. aeruginosa. 100 ult of (from left to right): $1^{\text {st }}$, $2^{\text {nd }}, 3^{\text {rd }}$ rinse water were added to each well.

Fig. 2.S - Rinse water of EOLFG, EOLSG, EOLGG plugs loaded with polymyxin B (from Fig. 1.b) and checked for cell growth inhibition of $S$. marcescens. $100 \mathrm{ult}$ of (from left to right): $1^{\text {st }}$, $2^{\text {nd }}, 3^{\text {rd }}$ rinse water were added to each well.

Fig. 3.S- Inhibition by polymyxin B released from aerogels of Gram-negative Hafnia alvei cell growth. Central well (1), $30 \mu \mathrm{g}$ (equivalent to 22 nanomoles) of free polymyxin B. Lateral wells: plugs of loaded EOLFG (2), control EOLFG (3); loaded EOLSG (4), control EOLSG (5); loaded EOLGG (6), control EOLGG (7).

Fig. 4.S - Rinse water of EOLFG, EOLSG, EOLGG plugs loaded with nisin (from Fig. 2.a) and checked for cell growth inhibition of E. faecalis. 100 ult of (from left to right): $1^{\text {st }}, 2^{\text {nd }}, 3^{\text {rd }}$ rinse water were added to each well.

Fig. 5.S - Inhibition of C. tyrobutirycum growth by lysozyme released from EOLFG aerogel: (1) $125 \mu \mathrm{g}$ (equivalent to 8.7 nanomoles) of free lysozyme. Plugs of: (2) loaded EOLFG, (3) control EOLFG.

Fig. 6.S - Time course of commercial C. lipolitica rrelease in water solution from "loaded" hydrogel plugs of EOLFG, EOLSG and EOLGG. Each time point was performed in triplicate on separately prepared plugs and is expressed as the average percentage of the "theoretical" total lipase activity loaded.

Fig. 7.S - Pore size distribution plots of EOLFG (a), EOLSG (b), EOLGG (c) 

Supplementary dała lab. 1.S - Time course of protease release in water from "loaded" hydrogel plugs of EOLFG, EOLSG and EOLGG. Experiments were performed in triplicate on independently prepared plugs.

Average activity values and percentage of the "theoretical" maximum activity loaded into the aerogels are reported for each time point, with standard deviations. Protease activity is expressed as $\Delta$ O.D. at $440 \mathrm{~nm} / 10 \mathrm{~min} / \mathrm{ml}$.

\begin{tabular}{|c|c|c|c|c|c|c|}
\hline \multirow[b]{2}{*}{ Time, $\mathbf{h}$} & \multicolumn{2}{|c|}{ EOLFG } & \multicolumn{2}{|c|}{ EOLSG } & \multicolumn{2}{|c|}{ EOLGG } \\
\hline & $\begin{array}{l}\text { Protease } \\
\text { activity }\end{array}$ & $\begin{array}{c}\text { Theoretical } \\
\max , \%\end{array}$ & $\begin{array}{l}\text { Protease } \\
\text { activity }\end{array}$ & $\begin{array}{c}\text { Theoretical } \\
\max , \%\end{array}$ & $\begin{array}{l}\text { Protease } \\
\text { activity }\end{array}$ & $\begin{array}{c}\text { Theoretical } \\
\max , \%\end{array}$ \\
\hline 1 & $23.8 \pm 1.2$ & $54.3 \pm 6.0$ & $17.5 \pm 13.1$ & $45.1 \pm 25.8$ & $11.2 \pm 4.0$ & $26.1 \pm 9.4$ \\
\hline 2 & $26.7 \pm 2.8$ & $60.5 \pm 3.2$ & $25.2 \pm 8.7$ & $68.1 \pm 8.7$ & $21.0 \pm 4.7$ & $49.1 \pm 11.0$ \\
\hline 3 & $34.0 \pm 4.7$ & $76.9 \pm 1.6$ & $29.5 \pm 12.0$ & $79.3 \pm 15.2$ & $24.2 \pm 6.4$ & $56.5 \pm 14.9$ \\
\hline 4 & $35.8 \pm 4.5$ & $81.2 \pm 2.8$ & $28.2 \pm 9.7$ & $76.3 \pm 9.4$ & $33.5 \pm 7.3$ & $78.3 \pm 17.1$ \\
\hline 5 & $39.7 \pm 0.9$ & $90.6 \pm 12.3$ & $35.0 \pm 4.7$ & $97.1 \pm 8.8$ & $34.0 \pm 4.7$ & $79.5 \pm 11.0$ \\
\hline 6 & $43.2 \pm 5.4$ & $97.8 \pm 3.3$ & $36.8 \pm 9.2$ & $100.8 \pm 2.6$ & $41.5 \pm 6.4$ & $97.0 \pm 14.9$ \\
\hline
\end{tabular}


Tab. 2.S - Time course of $C$. lipolitica release in water from "loaded" hydrogel plugs of EOLFG, EOLSG and EOLGG. Experiments were performed in triplicate on independently prepared plugs.

Average activity values and percentage of the "theoretical" maximum activity loaded into the aerogels are reported for each time point, with standard deviations. Lipase activity is expressed as $\Delta$ O.D. at $410 \mathrm{~nm} / \mathrm{min} / \mathrm{ml}$.

\begin{tabular}{ccccccc}
\hline & \multicolumn{2}{c}{ EOLFG } & \multicolumn{2}{c}{ EOLSG } & \multicolumn{2}{c}{ EOLGG } \\
Time, $\mathrm{h}$ & $\begin{array}{c}\text { Lipolytic } \\
\text { activity }\end{array}$ & $\begin{array}{c}\text { Theoretical } \\
\text { max, } \%\end{array}$ & $\begin{array}{c}\text { Lipolytic } \\
\text { activity }\end{array}$ & $\begin{array}{c}\text { Theoretical } \\
\text { max, } \%\end{array}$ & $\begin{array}{c}\text { Lipolytic } \\
\text { activity }\end{array}$ & $\begin{array}{c}\text { Theoretical } \\
\text { max, \% }\end{array}$ \\
1 & $0.7 \pm 0.1$ & $4.5 \pm 2.4$ & $1.4 \pm 0.4$ & $7.5 \pm 1.9$ & $2.2 \pm 1.2$ & $10.1 \pm 5.5$ \\
2 & $0.8 \pm 0.4$ & $5.5 \pm 3.1$ & $2.4 \pm 1.8$ & $13.0 \pm 10.0$ & $3.3 \pm 1.8$ & $15.3 \pm 8.6$ \\
3 & $1.0 \pm 0.5$ & $6.8 \pm 4.1$ & $2.2 \pm 0.7$ & $11.6 \pm 4.2$ & $3.6 \pm 1.8$ & $16.7 \pm 7.8$ \\
4 & $1.1 \pm 0.6$ & $7.3 \pm 4.7$ & $3.2 \pm 0.8$ & $17.2 \pm 5.6$ & $3.6 \pm 1.6$ & $16.9 \pm 6.5$ \\
5 & $1.4 \pm 0.8$ & $9.4 \pm 5.8$ & $3.2 \pm 1.0$ & $17.1 \pm 6.2$ & $3.3 \pm 0.9$ & $15.6 \pm 4.2$ \\
6 & $1.9 \pm 1.0$ & $12.8 \pm 7.8$ & $3.4 \pm 1.3$ & $18.5 \pm 7.6$ & $3.8 \pm 0.9$ & $17.9 \pm 3.3$ \\
25 & $4.8 \pm 0.7$ & $29.5 \pm 8.0$ & $4.3 \pm 0.9$ & $22.4 \pm 2.3$ & $4.4 \pm 0.6$ & $21.5 \pm 4.9$ \\
\hline 30 & $4.3 \pm 0.1$ & $28.8 \pm 11.6$ & $3.4 \pm 0.7$ & $18.0 \pm 2.0$ & $4.9 \pm 0.7$ & $24.0 \pm 4.7$ \\
\hline
\end{tabular}

